\title{
1 Urban sediment supply to streams from hillslope sources
}

2 Authors: Kathryn L. Russell ${ }^{1}$, Geoff J. Vietz ${ }^{1}$, Tim D. Fletcher ${ }^{1}$

3 Affiliations: ${ }^{1}$ University of Melbourne, 500 Yarra Boulevard, Burnley, VIC, Australia

* Corresponding author: kathryn.russell@unimelb.edu.au

Keywords: Sediment supply; Sediment budget; Urbanization; Geomorphology; Stormwater;

6 Connectivity

\section{Abstract}

8 Coarse-grained sediments supplied to a stream, in concert with the flow regime, play an important

9 role in channel form and functioning, but are poorly understood in urban catchments. Improved 10 knowledge of coarse-grained $(>0.5 \mathrm{~mm})$ sediment sources and supply rates will underpin strategies

11 to mitigate impacts of urbanization on streams. We quantified key hillslope (i.e. non-channel) sources of sediment in urban areas by monitoring coarse-grained sediment yields from nine street-scale stormwater catchments over one year. From our observations, we developed a suburban hillslope sediment budget and a conceptual model of the response of hillslope coarse-grained sediment supply to different levels of urbanization. Coarse-grained sediment supply from the urban land surface was substantial. The highest unit-area yields came from infill construction sites $(2,800 \mathrm{~kg} / \mathrm{ha} / \mathrm{yr})$, followed by gravel surfaces $(740 \mathrm{~kg} / \mathrm{ha} / \mathrm{yr})$, grass/mulch surfaces $(84 \mathrm{~kg} / \mathrm{ha} / \mathrm{yr})$, then impervious surfaces $(21$ $\mathrm{kg} / \mathrm{ha} / \mathrm{yr}$ ), with the latter still producing yields far above background conditions. In typical suburban catchments grass and mulch surfaces and construction areas were key sources, with gravel and impervious surfaces making smaller contributions. Small source areas were important, for example construction produced $32 \%$ of sediment from $0.5 \%$ of the area. Connectivity of sediment sources to impervious surfaces, and hence to drainage systems, was important in driving sediment yields. Our conceptual model indicates that that hillslope coarse-grained sediment supply increases with 
urbanization from natural to suburban conditions as connectivity increases, then declines with higher levels of urbanization as sources become scarcer. Impervious surfaces provide sources and supply pathways of coarse sediment, but also increase sediment transport capacity, causing severely supplylimited conditions and reducing the persistence of bed sediments in streams. When reducing hydrological connectivity to address the urban flow regime, consideration should be given to maintaining coarse-grained sediment supply through bypass or replenishment arrangements, to help reduce stream degradation and maintain form and functioning.

\section{INTRODUCTION}

Urbanization fundamentally alters a suite of hydrological and earth surface processes, causing widespread ecological degradation (Meyer et al., 2005; Walsh et al., 2005b). Impervious land cover and efficient stormwater drainage systems to streams drive increased and more responsive runoff and streamflow patterns, causing channel erosion and producing in-stream conditions inhospitable to biota. Urban streams tend to be enlarged (Chin, 2006; Paul and Meyer, 2001) with reduced bed sediment depth (Vietz et al., 2014) and increased substrate particle size (Finkenbine et al., 2000; Hawley et al., 2013; Utz and Hilderbrand, 2011). Such geomorphic adjustments have wide-ranging impacts on the values of urban streams, including practical concerns (damage to infrastructure, loss of land), ecological impacts (loss of habitat, benthic plants and sensitive biota), and reductions in amenity and aesthetics (Booth, 1991; Gurnell et al., 2007; Smith et al., 2016; Walsh et al., 2012).

Studies have begun to unravel the processes driving urban stream degradation, focusing mainly on the altered hydrology of urban systems (Bunn and Arthington, 2002; Burns et al., 2015; Fletcher et al., 2013). The fluvial geomorphology of a stream, however, is a product of the balance between flow and sediment supply (Lane, 1955; Mackin, 1948). While the role of urban stormwater runoff in driving increased sediment transport capacity in streams is receiving growing recognition, the response of sediment supply to urbanization is poorly understood (Russell et al., 2017; Vietz et al., 2016). Coarse- 
grained sediment, defined here as particles $>0.5 \mathrm{~mm}$ (coarse sand and greater) after Houshmand et al. (2014), is particularly relevant to stream ecology, providing bed material that forms the substrate for ecological communities and processes (Hawley and Vietz, 2016). Altered coarse-grained sediment supply could have a role in either exacerbating (if reduced) or mitigating (if increased) the impacts of increased urban stormwater flows (Lane, 1955).

Moreover, we need to specifically understand hillslope (urban land surface) sources of sediment in urban areas, as distinct from in-channel sources. Catchment-scale urban sediment budget studies tend to find that channel erosion is the principal source of coarse-grained sediment (Nelson and Booth, 2002; Trimble, 1997). However, channel erosion is a response to altered flow and sediment inputs, and to manage channel degradation we must look upstream of the channel to better understand these drivers, i.e. on the hillslopes. Avoiding urbanization impacts to headwater streams requires maintenance of hillslope sediment supply at levels commensurate with the increase in sediment transport capacity.

Recent work has greatly increased our understanding of urban hillslope sediment yields, pointing to a consistent pattern of elevated sediment supply from the hillslopes of urban catchments (Gellis et al., 2017; Smith et al., 2011; Smith and Wilcock, 2015). The key sediment sources and the processes driving the increase were unclear in these studies, as it was expected that land stabilisation would lead to decreased sediment loads (Gurnell et al., 2007; Wolman, 1967). The contribution of infill construction has long been recognised (Leopold and Dunne, 1978; Smith et al., 2011), while Smith and Wilcock (2015) expanded this to include infrastructure maintenance, yard work, building renovations, and accidental sediment spills as potential sources in mature suburbs. Street residue, residential lawns, parks, forested areas and hillslopes were invoked as potential sources by Gellis et al. (2017). To assist in the conceptualisation of sediment sources and supply pathways, the urban coarse-grained sediment cascade from hillslopes to stream channels was outlined (Figure 1), sensu Taylor (2007). The processes by which coarse-grained sediment can reach impervious surfaces include decay of 
impervious surfaces themselves, fluvial detachment and transport from adjacent sources (e.g. raindrop impact, rill and interrill erosion), traction of particles from adjacent sources by vehicles and pedestrians and spills of construction materials or waste. The relative importance of these processes, and of the different urban land cover types, needs to be established. These supply pathways are also dependent on sediment connectivity at the hillslope (i.e. the catchment of a stormwater pit or impervious surface) scale.

Usually only a small proportion of sediment which is eroded from a land surface reaches a basin outlet (Walling, 1983), with the remainder stored in hillslope, channels, floodplain and lake deposits. The sediment (dis)connectivity framework developed by Fryirs et al. (2007a) conceptualises impediments to sediment connectivity between different landscape compartments or sediment storages to unravel the internal dynamics of sediment storage and flux in a catchment. These impediments are classified as (i) buffers, which prevent sediment from entering the channel network from hillslopes; (ii) barriers, which impede sediment movement along the channel; and (iii) blankets, which smother other landforms and protect them from reworking. While the specific definitions of these elements depend on the temporal and spatial scale of observation, we can define them at a useful scale for understanding urban sediment connectivity. We apply these concepts by framing urban land surfaces as 'hillslopes', and stormwater pipes and gutters as well as open drains and streams as 'channels'. While urban hillslopes are generally highly connected to stormwater networks, their connectivity is impeded by buffers including fences, walls, well-grassed areas, and disconnected topographic low points. Within the stormwater drainage network, sediment traps, gross pollutant traps (GPTs), sediment ponds, debris blockages and low-gradient pits and pipes can form barriers which impede sediment movement downstream. Blankets exist in urban areas at two scales: i) features that smother sedimentation on the urban land surface, such as grass, mulch, pebble toppings and impervious surfaces; and (ii) features that smother sedimentation in pipes, channels and floodplains, such as bed armour. The spatial complexity of land cover and drainage patterns of the built environment will likely produce very complex hillslope connectivity patterns that affect urban sediment supply. 


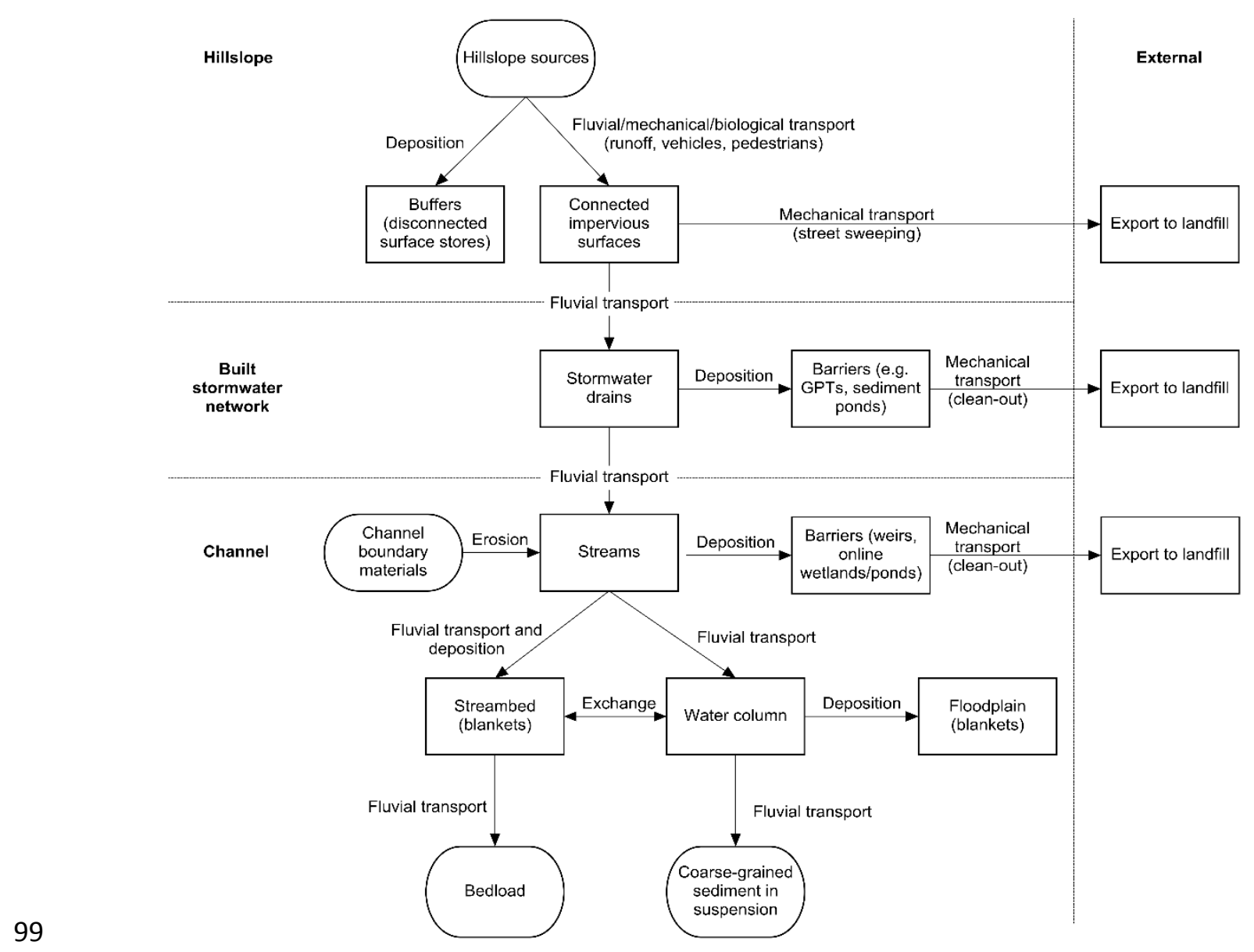
built stormwater network, and into channels. Key inputs and outputs are shown in rounded boxes, storages in rectangular boxes, and processes on arrows.

The objectives of this research are to identify and quantify coarse-grained sediment sources in urban hillslope catchments (where urban hillslopes are considered urban land surfaces that drain to the stormwater network), to conceptualise supply pathways and connectivity, and to subsequently understand the processes driving hillslope sediment supply to urban streams. Key questions are:

1. What are the typical rates of coarse-grained sediment supply from different urban land cover types?

2. What are the dominant sources of coarse-grained sediment in typical urban and suburban catchments? 
3. What is the role of sediment connectivity in limiting or enhancing coarse-grained sediment supply?

4. What is the likely response of hillslope coarse-grained sediment supply to different levels of urbanization intensity?

Hillslope sediment supply monitoring was undertaken in the upper Scotchmans Creek catchment in eastern Melbourne, Australia (Figure 2). The catchment has typical suburban land use with average total imperviousness ( $\mathrm{TI}$ ) of $47.4 \%$ and effective imperviousness (El; the proportion of land covered by impervious surfaces directly connected to a stormwater drainage network) of $46.8 \%$ (Russell et al., 2018). Land use is mostly residential with the remainder a mix of commercial, infrastructure and utilities, and cultural and sporting facilities. Sealed road surfaces make up $13 \%$ of the catchment area, and unsealed roads are virtually absent. The pervious areas are well-vegetated, with tree canopy covering over half the pervious surfaces in the catchment. 

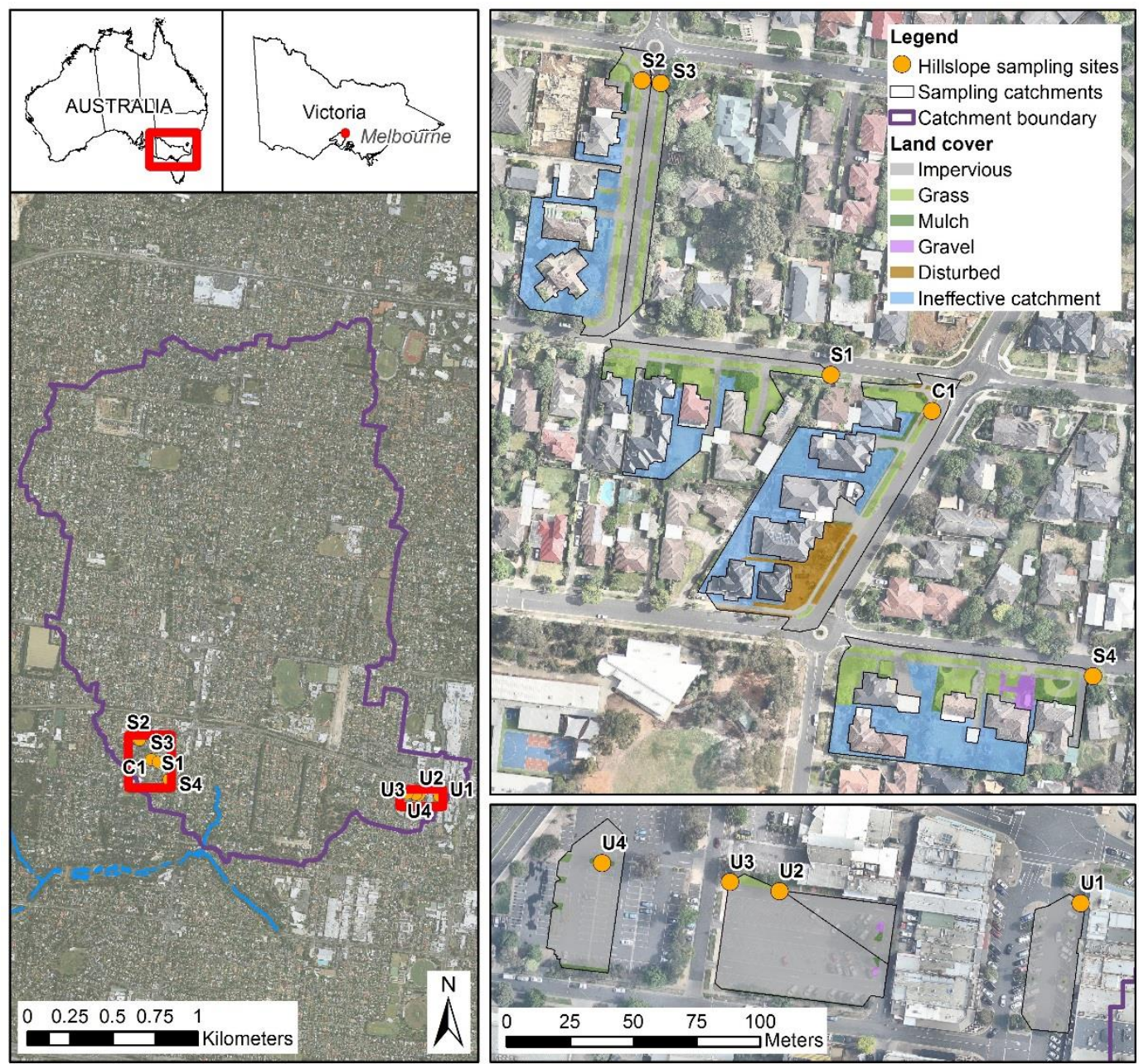
and $\mathrm{C} 1$ is suburban with construction site.

Stream burial and drainage network extension are significant in the catchment, increasing the total drainage density (including underground pipes) to around $20 \mathrm{~km} / \mathrm{km}^{2}$, probably more than 20 times higher than natural conditions. Pre-urban drainage density was estimated at $0.7 \mathrm{~km} / \mathrm{km}^{2}$ from the sum of open channels and trunk drainage pipes (considered likely to be buried streams), which is similar to drainage densities of nearby undeveloped catchments $\left(0.7-1.2 \mathrm{~km} / \mathrm{km}^{2}\right.$; Russell et al. (2018)). Additional concentrated drainage paths on the urban surface like street and roof gutters, and private drainage pipes, further increase the urban drainage density by at least as much again (Walsh et al., 2016). Where open channels remain unburied, they are stabilised with large rock. Scotchmans Creek 
is incised compared to nearby natural analogues, has few bars and benches, and low wood loads (Vietz et al., 2014). Channel enlargement, simplification and rock-lining are indicative of channel erosion in the past, which probably occurred in response to the urban flow and sediment regime. In addition to geomorphic impacts, the creek suffers from degraded water chemistry, elevated temperature (Hatt et al., 2004), and severely degraded aquatic ecosystems (Walsh, 2004).

The catchment has separate stormwater and sewer systems and few stormwater treatment features, so most stormwater reaches the stream untreated. Gross pollutant traps (GPTs) and ponds treat around $12 \%$ of the catchment.

Urbanization of the catchment occurred mostly during the 1950 s to 1970 s, although infill and renewal construction works are constantly occurring. The instantaneous proportion of land under construction in September 2017 was estimated to be 1.5\%, and the average renewal rate over the previous 6 years was estimated to be $2.2 \%$ of the catchment surface per year (estimated from NearMap imagery, 20092017). The intensity and type of construction activity are typical of renewal and infill development across the established suburbs of Melbourne (Department of Environment Land Water \& Planning, 2016).

The catchment is relatively flat (relief ratio $1.4 \%$ ), is dominated by sandstone and siltstone surface geology, and receives a mean annual rainfall of approximately $800 \mathrm{~mm}$. Soil type is mapped at the regional scale as yellow duplex soils (Chromosols) (ASRIS, 2018), which are moderately susceptible to water erosion and not susceptible to mass movement or wind erosion (Rowan et al., 2000).

\section{1}

\section{Hillslope catchment mapping}

Catchment land cover mapping was undertaken in detail for nine street-scale stormwater catchments 
categories (see Figure 3 for examples): general suburban land (24-73\% Tl; 4 sites), high imperviousness urban land (95-99\% TI; 4 sites), and suburban land with construction (34\% TI; 1 site). The catchments were selected first through GIS and then field inspection. Selection was targeted towards stormwater catchments that contained a mix of land-cover types present in the broader catchment. We were also guided by practical concerns about the type of pit that could accommodate the monitoring equipment. The selected suburban catchments were representative of the broader catchment, which is relatively homogeneous in its land-cover arrangements. They included a mix of older and newer houses and a mix of single-dwelling and subdivided lots. The urban catchments included mainly car parks, roads and footpaths as well as some surrounding landscaping elements (garden beds, lawns, street trees). These are considered representative of the shopping-strip type commercial areas in the catchment, but highly impervious industrial areas may differ. The construction areas in C1 were typical in their scale (one single-dwelling replacement and one two-lot subdivision), construction methods, timelines (completion in around one year) and sediment control arrangements (virtually nonexistent).

Land cover was categorised as (i) impervious at ground level (road/path/private), (ii) grass/mulch, (iii) gravel, (iv) construction, or (v) ineffective (i.e. areas with low sediment connectivity) (Table 1). Note that gravel surfaces include driveways, paths and ornamental toppings, which typically include a mix of size classes (clay, sand, gravel), not just particles coarser than $2 \mathrm{~mm}$. 

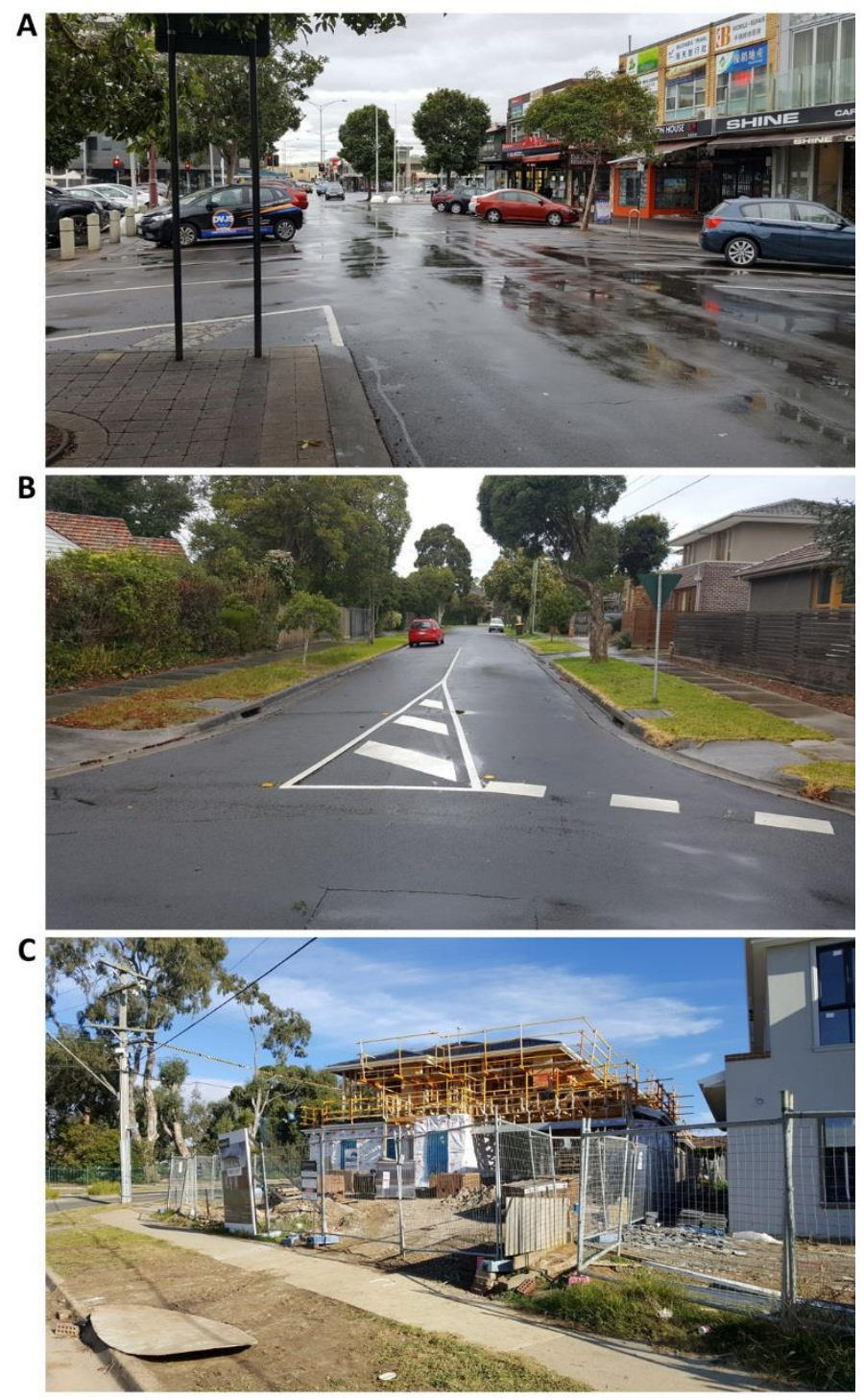

178 Figure 3 Typical urban development in: (A) high imperviousness urban catchments (U1), (B) with construction (C1) (see Figure 2 for location details). 


\begin{tabular}{|c|c|c|c|c|c|c|c|c|}
\hline \multirow[t]{2}{*}{ ID } & \multirow{2}{*}{$\begin{array}{l}\text { Catchment } \\
\text { area (ha) }\end{array}$} & \multirow{2}{*}{$\begin{array}{l}\text { Drainage } \\
\text { density } \\
\left(\mathrm{km} / \mathrm{km}^{2}\right)^{1}\end{array}$} & \multicolumn{6}{|c|}{ Land cover (\%) } \\
\hline & & & $\begin{array}{l}\text { Ineffective } \\
\text { catchment } \\
\text { area }^{2}\end{array}$ & $\begin{array}{l}\text { Impervious } \\
\text { (roof) }\end{array}$ & $\begin{array}{l}\text { Impervious (non- } \\
\text { roof) }\end{array}$ & Grass/Mulch & Gravel $^{4}$ & Construction \\
\hline U1 & 0.10 & 60 & $0.0 \%$ & $0.0 \%$ & $99.5 \%$ & $0.5 \%$ & $0.0 \%$ & $0.0 \%$ \\
\hline U2 & 0.05 & 79 & $0.0 \%$ & $0.0 \%$ & $96.3 \%$ & $1.7 \%$ & $2.1 \%$ & $0.0 \%$ \\
\hline U3 & 0.22 & 27 & $0.0 \%$ & $0.0 \%$ & $96.3 \%$ & $3.4 \%$ & $0.3 \%$ & $0.0 \%$ \\
\hline U4 & 0.13 & 45 & $0.0 \%$ & $0.0 \%$ & $94.6 \%$ & $5.4 \%$ & $0.0 \%$ & $0.0 \%$ \\
\hline S1 & 0.17 & 51 & $26.1 \%$ & $0.0 \%$ & $29.8 \%$ & $44.0 \%$ & $0.0 \%$ & $0.0 \%$ \\
\hline S2 & 0.22 & 54 & $50.8 \%$ & $0.0 \%$ & $35.2 \%$ & $14.0 \%$ & $0.0 \%$ & $0.0 \%$ \\
\hline S3 & 0.07 & 130 & $0.0 \%$ & $0.0 \%$ & $72.5 \%$ & $27.4 \%$ & $0.1 \%$ & $0.0 \%$ \\
\hline S4 & 0.29 & 33 & $44.6 \%$ & $0.0 \%$ & $23.8 \%$ & $27.6 \%$ & $4.0 \%$ & $0.0 \%$ \\
\hline $\mathrm{C} 1$ & 0.31 & 38 & $36.6 \%$ & $0.0 \%$ & $34.3 \%$ & $10.8 \%$ & $0.0 \%$ & $18.2 \%$ \\
\hline
\end{tabular}

${ }^{1}$ Drainage density based on length of street gutter per catchment area

${ }^{2}$ Ineffective catchment areas are those areas disconnected by sediment barriers or buffers (e.g. fenced backyards, poorly drained depressions)

${ }^{4}$ Gravel surfaces can include a mix of size classes including sand and clay, not just particles $>2 \mathrm{~mm}$

The delineation of ineffective areas required a manual GIS and field-based assessment of 'buffers', sediment storage areas which prevent sediment from hillslopes entering the urban drainage system (Fryirs et al., 2007a) (Figure 4). Firstly, the catchment boundary was delineated using a $1 \mathrm{~m}$ resolution LiDAR digital elevation model and aerial imagery, then potential sediment buffers (consisting here of 190 fences and sinks) were identified and the area they disconnected from the catchment was mapped,

191 then finally the catchment boundary, buffers and ineffective catchment areas were verified by field 192 inspection during a rainfall event. Roofs were plumbed directly into the underground stormwater system and were assumed not to contribute to the hillslope surface catchments. 


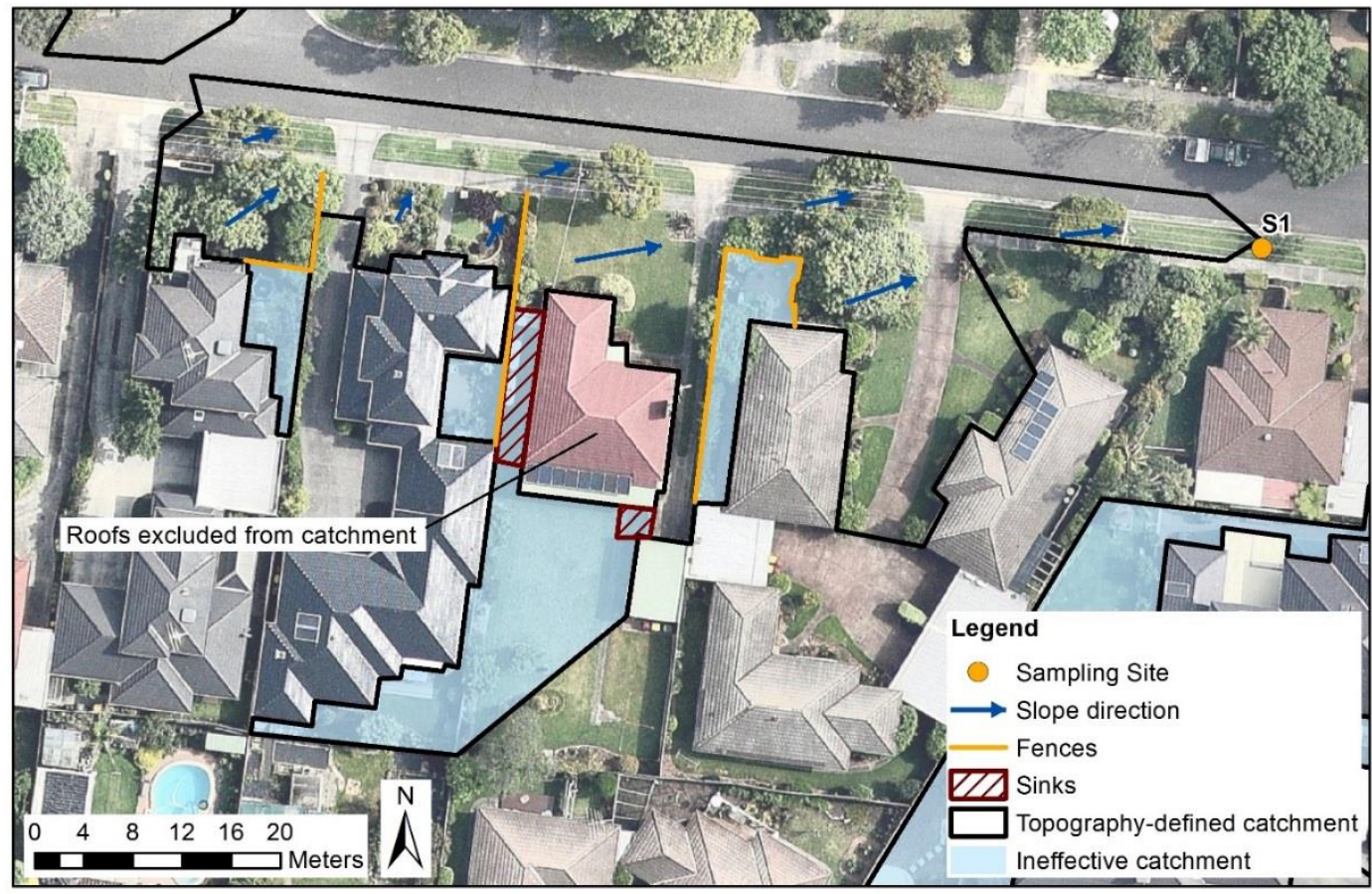

Example of assessment of sediment buffers and ineffective catchment areas, catchment S1 (see Figure 2 for location details).

A custom-made coarse sediment trap was installed in the side-entry stormwater pit at the outlet of each hillslope catchment. The trap was an inverted pyramid-shaped basket with an open top, measuring $900 \mathrm{~mm}$ long parallel to the pit inlet (the full length of the pit), $150 \mathrm{~mm}$ wide perpendicular to the inlet (one-quarter the width of the pit), and $600 \mathrm{~mm}$ deep. The trap was constructed from polyester mesh with an aperture size of $470 \mu \mathrm{m}$. The trap was installed just below the pit inlet, stretched between two steel bars embedded in the pit wall on each side of the inlet (Figure 5). Aluminium flashing was installed to direct stormwater into the trap and prevent bypass. The trap spanned a quarter of the pit width to allow overflow and maintain the hydraulic performance of the pit. This width was adequate to ensure that flow from the inlet was directed into the trap and did not bypass except in case of blockage. Some traps (particularly urban site U1) became clogged with litter and organic matter and therefore likely overtopped with flow. While we could not fully assess turbulent flow dynamics or capture efficiency in the traps, our design is similar to a side-entry pit trap 
210 (SEPT) for gross pollutant removal which has been field-tested. In a four-month field trial of SEPTs with

$2115 \mathrm{~mm}$ mesh size, Allison et al. (1998) found a trapping efficiency of $62-75 \%$ of the total gross pollutant

212 load. Given most of that material was human-derived or organic, its efficiency would be expected to

213 be even higher for denser inorganic sediments. In our traps, we did not observe any evidence of

214 coarse-grained sediments bypassing the traps, except in urban site U3 on 11 December 2017 (after

215 the most intense rainfall event), when sediment was observed in the base of the stormwater pit, but

216 very little was in the trap.

217 Coarse-grained sediment samples were collected from the hillslope sediment traps 9 times from 11

218 May 2017 to 24 April 2018. Sampling was undertaken at approximately one-month intervals from May

2192017 to January 2018, then the final sample was taken after a further 3-month interval. The total

220 rainfall that occurred over the 50-week sampling period was $591 \mathrm{~mm}$ (Bureau of Meteorology, 2018),

$22126 \%$ lower than the mean annual rainfall of $803 \mathrm{~mm}$, indicating that this was a relatively dry year. The

222 most intense event had a maximum 6-minute rainfall total of $9.2 \mathrm{~mm}$, with an annual exceedance

223 probability of around $17 \%$ (one in six years). One sediment trap (C1) was installed prior to the others

224 as a pilot site, and a further two samples were collected for the period of 20 April 2017 to 11 May

2252017 for that site. This period covered moderate-intensity events (maximum 6-minute rainfall total of

$226 \quad 2.4 \mathrm{~mm}$ ) with an additional total rainfall of $101 \mathrm{~mm}$. 

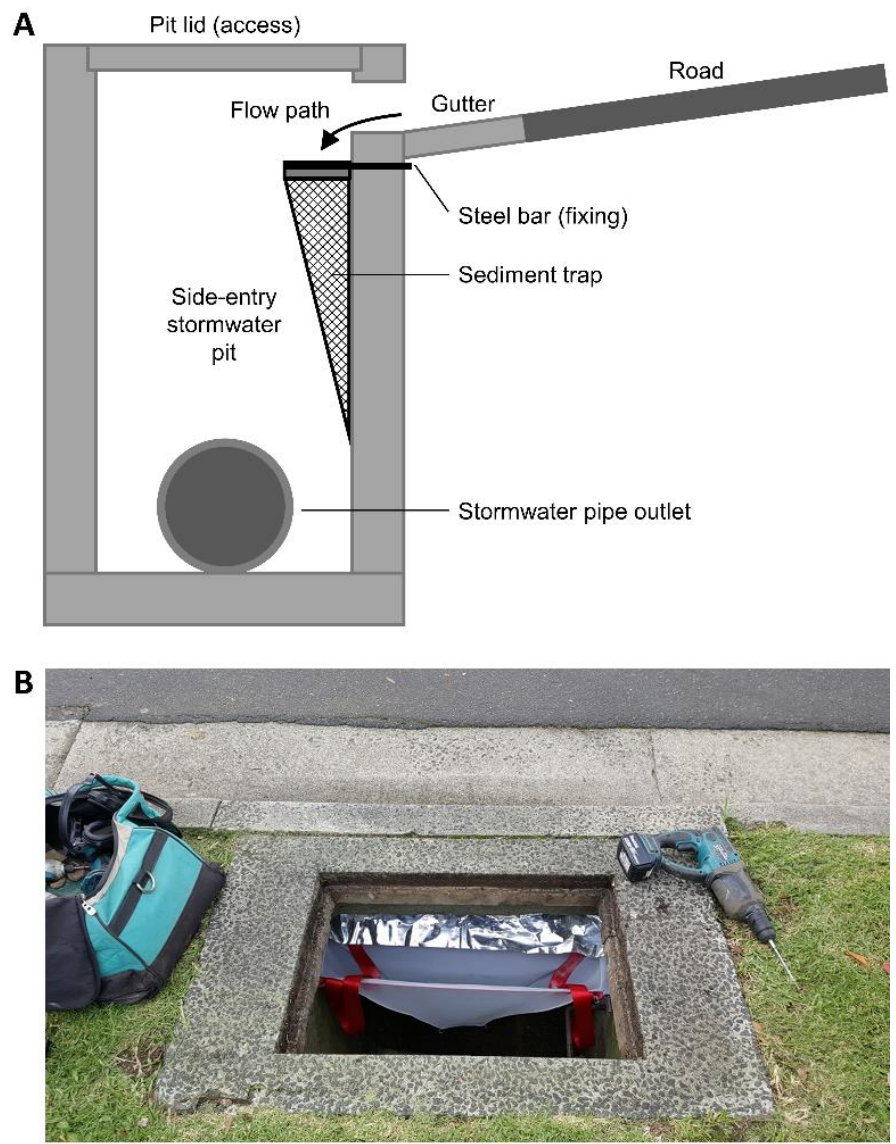

(A) Schematic cross-section diagram; and (B) example of coarse sediment trap. six litres of material was present, exceeding the capacity of our sampling equipment. In some of the traps (particularly the suburban ones), the trapped material was overwhelmingly organic matter. In these cases the subsample was made as large as possible (up to six litres), to allow better representation of the trapped material and to maximise the amount of inorganic coarse sediment collected. In the site with active construction, the material was mostly inorganic and a smaller subsample (one to three litres) was used for analysis. 
were discarded. This study focused solely on sediment coarser than $0.5 \mathrm{~mm}$, which is considered more beneficial than finer sediments for stream health (Hawley and Vietz, 2016; Houshmand et al., 2014; Russell et al., 2017). Organic matter was carefully washed off the samples and discarded during wet sieving. The resulting coarse sample was dry sieved through 5 sieves with descending aperture sizes ranging from $5 \mathrm{~mm}$ to $0.8 \mathrm{~mm}$. Each fraction was weighed to determine the particle size distribution (PSD; also referred to as grain size distribution (GSD) in the literature). The specific annual sediment yield for $>0.5 \mathrm{~mm}$ and $>2 \mathrm{~mm}$ size classes was estimated as the sum of the event loads, divided by the catchment area, and multiplied by a correction factor for the sampling period rainfall. The correction factor (mean annual rainfall divided by total rainfall over the sampling period) was applied to extrapolate the sampled yields to annual yields. Extrapolation to an annualised yield using mean annual rainfall was undertaken only for comparison between datasets with different sampling periods, and should not be considered to represent the actual long-term average annual yield.

\section{4}

\section{Monthly yield-rainfall relationships}

Temporal variability in coarse-grained sediment yield over longer-term (approximately monthly) timescales was explored by inspection of time-series, and fitting of regression models between rainfall and specific yield for each hillslope catchment. Exploratory data analysis revealed that, for most catchments, the primary variable driving variability was total rainfall in the period between samples, and that this was a more plausible predictor than the maximum rainfall intensity over durations of 6 minutes to 2 hours (evaluated using the Akaike information criteria; AIC; Burnham and Anderson (2003)). Rainfall intensity may be more important in driving variability over shorter time scales (i.e. single-event or sub-event) but integrated rainfall depth was favoured here because of the longer period and potentially multiple events between samples. Linear regression models were fitted between the logarithms of total rainfall in the preceding period and specific coarse-grained sediment yield for each sample. Log transformations were required on dependent and independent variables to fulfil the assumptions of the general linear model. Goodness of fit of models was indicated by $\mathrm{R}^{2}$ 
and shown graphically. The time-series of loads for catchments which produced poorer model fits were interrogated to suggest alternative explanations for their temporal variation, in addition to rainfall variability.

\section{Estimation of typical unit land cover yields}

The sediment yield estimates were partitioned into supply from each land cover by fitting linear models between annual sediment load and area of each land cover type within each catchment. All variables were untransformed. These linear models allowed estimation of a typical sediment supply rate from each land cover type, and quantification of variability. Estimates for construction areas were based on only one catchment and therefore had high and unquantifiable uncertainty. Gravel surfaces were only present in four of the catchments, and their yields were highly variable (due partly to different types of gravel toppings being present, with different size classes and levels of compaction), which created difficulties in estimating sediment supply rates from this land cover type. Estimates for gravel surfaces were only produced for the $>0.5 \mathrm{~mm}$ sediment class. Yields were more variable for the $>2 \mathrm{~mm}$ size class and partitioning between grass/mulch and gravel surfaces was not possible. Instead, these surface types were lumped together. Estimates for lumped grass/mulch/gravel (i.e. all pervious) surfaces are useful in themselves because land cover mapping often only distinguishes between pervious and impervious surfaces and accurate mapping of gravel surfaces is rare.

\section{Hillslope supply for typical catchments}

Using the modelled typical sediment supply rates for each land cover type, and the catchment land cover mapping, hillslope sediment yields to the drainage network for typical urban and suburban catchments were estimated. Land cover proportions for typical urban and suburban catchments were derived from the area-weighted averages of the hillslope catchments, along with additional assessment of roof areas (which were not included in the hillslope catchments) within the study area 

sediment loads.

291 Table 2

Adopted land cover characteristics for typical urban and suburban catchments

\begin{tabular}{|c|c|c|c|c|c|c|}
\hline \multirow[t]{2}{*}{ Catchment land use } & \multicolumn{6}{|l|}{ Land cover (\%) } \\
\hline & $\begin{array}{l}\text { Ineffective } \\
\text { catchment area }\end{array}$ & $\begin{array}{l}\text { Impervious } \\
\text { (roof) }^{2}\end{array}$ & $\begin{array}{l}\text { Impervious } \\
\text { (non-roof) }\end{array}$ & $\begin{array}{l}\text { Grass/ } \\
\text { Mulch }\end{array}$ & Gravel & Construction \\
\hline Typical Urban & $0 \%$ & $30.0 \%$ & $67.0 \%$ & $2.6 \%$ & $0.5 \%$ & $0 \%$ \\
\hline Typical Urban with $0.5 \%$ construction & $0 \%$ & $29.9 \%$ & $66.7 \%$ & $2.5 \%$ & $0.4 \%$ & $0.5 \%$ \\
\hline Typical Suburban & $30.0 \%$ & $24.0 \%$ & $26.0 \%$ & $18.8 \%$ & $1.2 \%$ & $0 \%$ \\
\hline Typical Suburban with $0.5 \%$ construction & $30.2 \%$ & $23.9 \%$ & $25.9 \%$ & $18.4 \%$ & $1.2 \%$ & $0.5 \%$ \\
\hline
\end{tabular}

${ }^{1}$ Ineffective catchment areas (e.g. fenced backyards and poorly drained depressions) estimated at $60 \%$ of total pervious area (including construction areas) for suburban land use and zero for urban land use.

\section{RESULTS}

Measured hillslope coarse-grained sediment yields from the suburban stormwater pit catchments were, on average, higher than the urban catchments, and more variable (Figure 6). The catchment with active construction had a yield around ten times higher than the average of the suburban catchments.

Particle size distributions (Figure 7) showed that the suburban catchments produced more variable, but on average, slightly coarser sediments than the urban catchments, particularly in the range of 1$10 \mathrm{~mm}$. The construction site produced coarser material than the other suburban catchments, but was within the envelope of the general suburban catchments. The coarsest particle delivered to the 


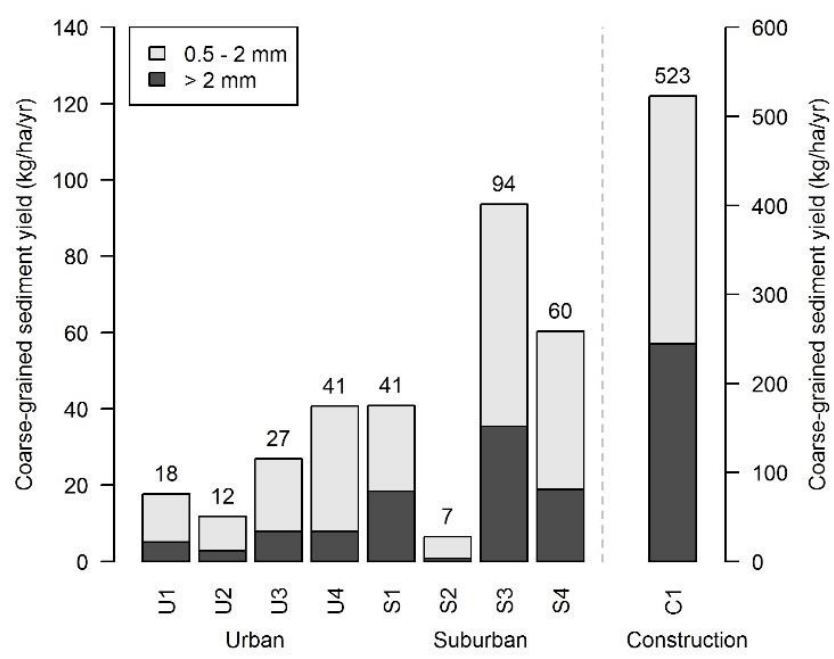

Annual coarse-grained ( $>0.5 \mathrm{~mm}$ ) sediment yield for monitored hillslope referring to the total. The $\mathrm{C} 1$ plot is shown on a different scale, as indicated by the right-hand y axis. See Figure $\mathbf{2}$ for location details.

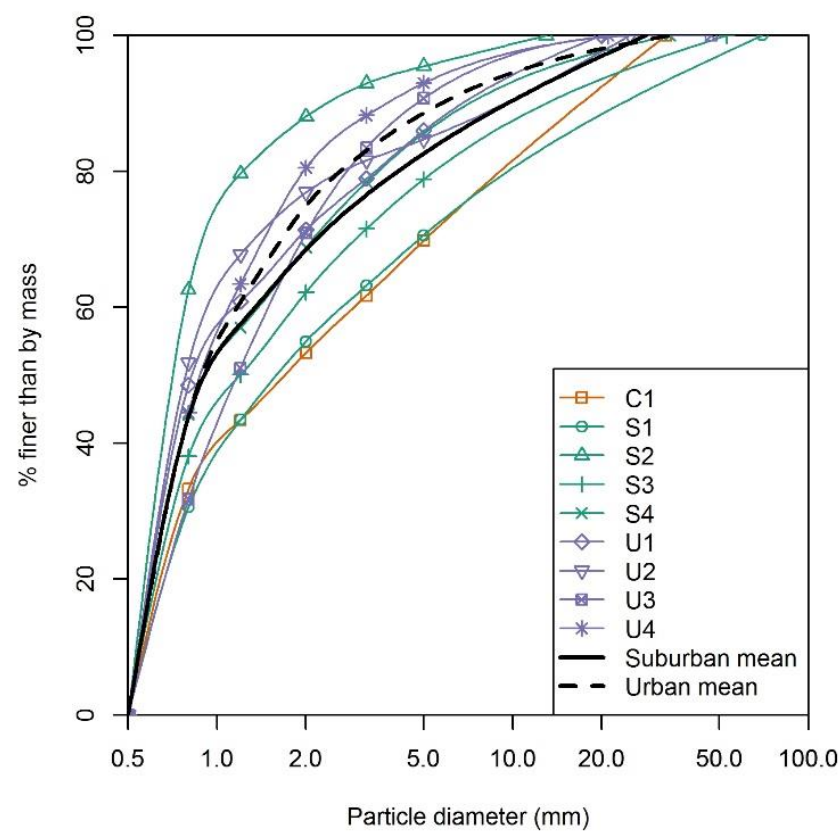

Particle size distributions (PSDs) for coarse-grained (> $0.5 \mathrm{~mm}$ ) upland yields 
314 Cumulative coarse-grained specific sediment yields for each catchment are shown in Figure 8, along with cumulative rainfall across the sampling period. For most catchments, the yield followed the same pattern as the rainfall. A notable exception was U3, which had a steady increase in cumulative yield in the first half of the sampling period, and a plateau in the second half despite higher rainfall, indicating sediment supply exhaustion.

Relationships between specific sediment yield and rainfall (Figure 9) were stronger for the suburban and suburban with construction catchments than the urban catchments. R-squared values for the suburban catchments $(0.67-0.84)$ indicate that total rainfall explains most of the variance in sediment yield over monthly timescales, and that other drivers play relatively minor roles. The urban catchments had weaker relationships, indicating that other factors (e.g. management actions such as street sweeping and gravel top-up) likely play a major role in their inter-monthly variability. In all catchments but U3, load increased non-linearly with rainfall. The exponent of that relationship (i.e. the slope of the line in log space; b) is indicative of catchment-scale erodibility, and unsurprisingly, tended to be higher for catchments with higher total yields. The exponent increased from urban $(b=$ 0.82-1.26) to suburban $(b=1.83-2.53)$ catchment conditions. A notable exception was the construction catchment, which had very high yield, but a relatively low R-squared value (0.53) and exponent $(b=1.19)$ compared to the other suburban catchments, indicating non-rainfall-related factors (e.g. construction stage or day-to-day practices) were important in driving sediment supply. Load increased non-linearly (except in U3) across the range of measured events (up to a six-year recurrence interval storm), showing no evidence of source exhaustion in large events. 

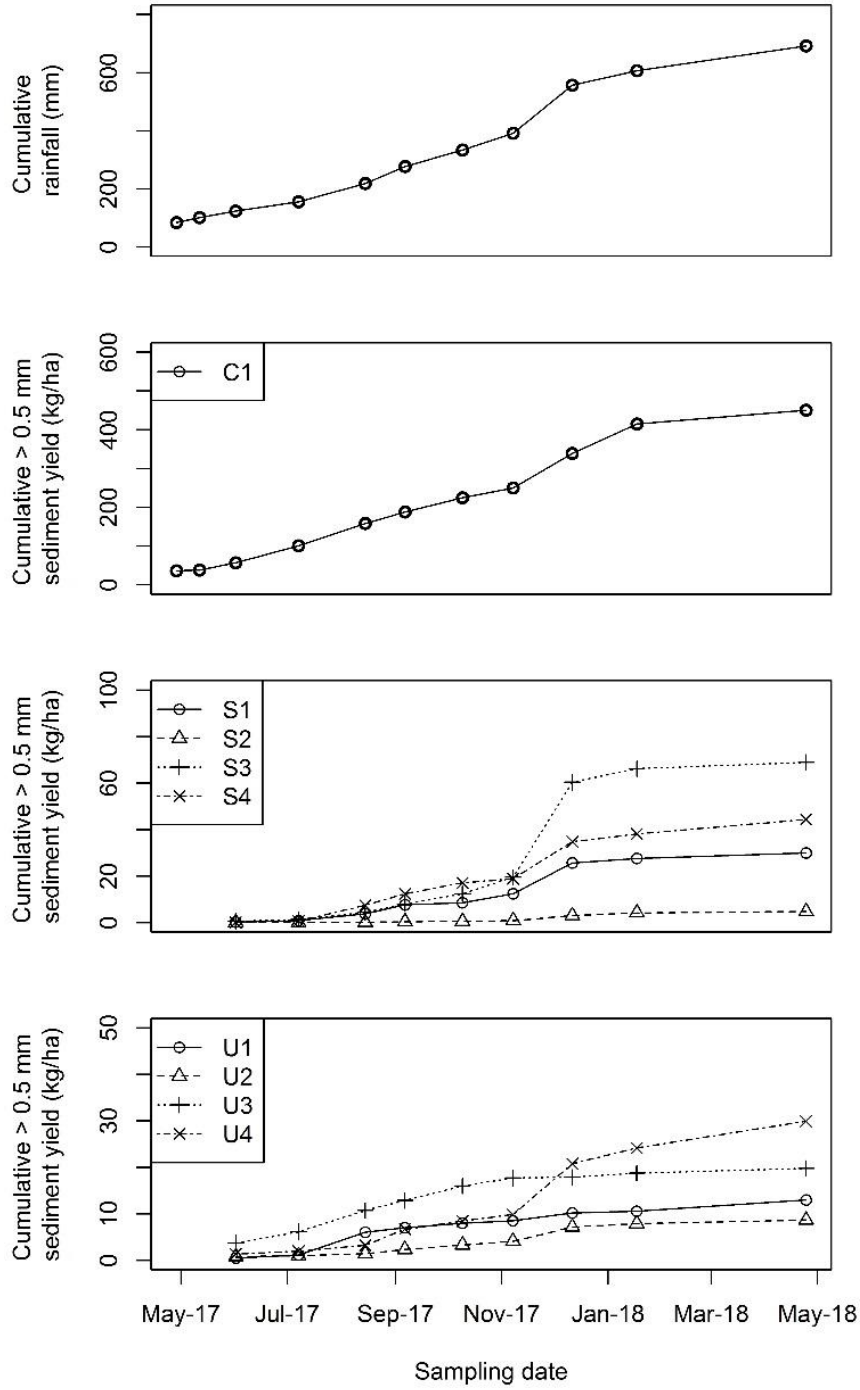

Figure $8 \quad$ Total rainfall and coarse-grained $(>0.5 \mathrm{~mm})$ sediment yield in the period between 


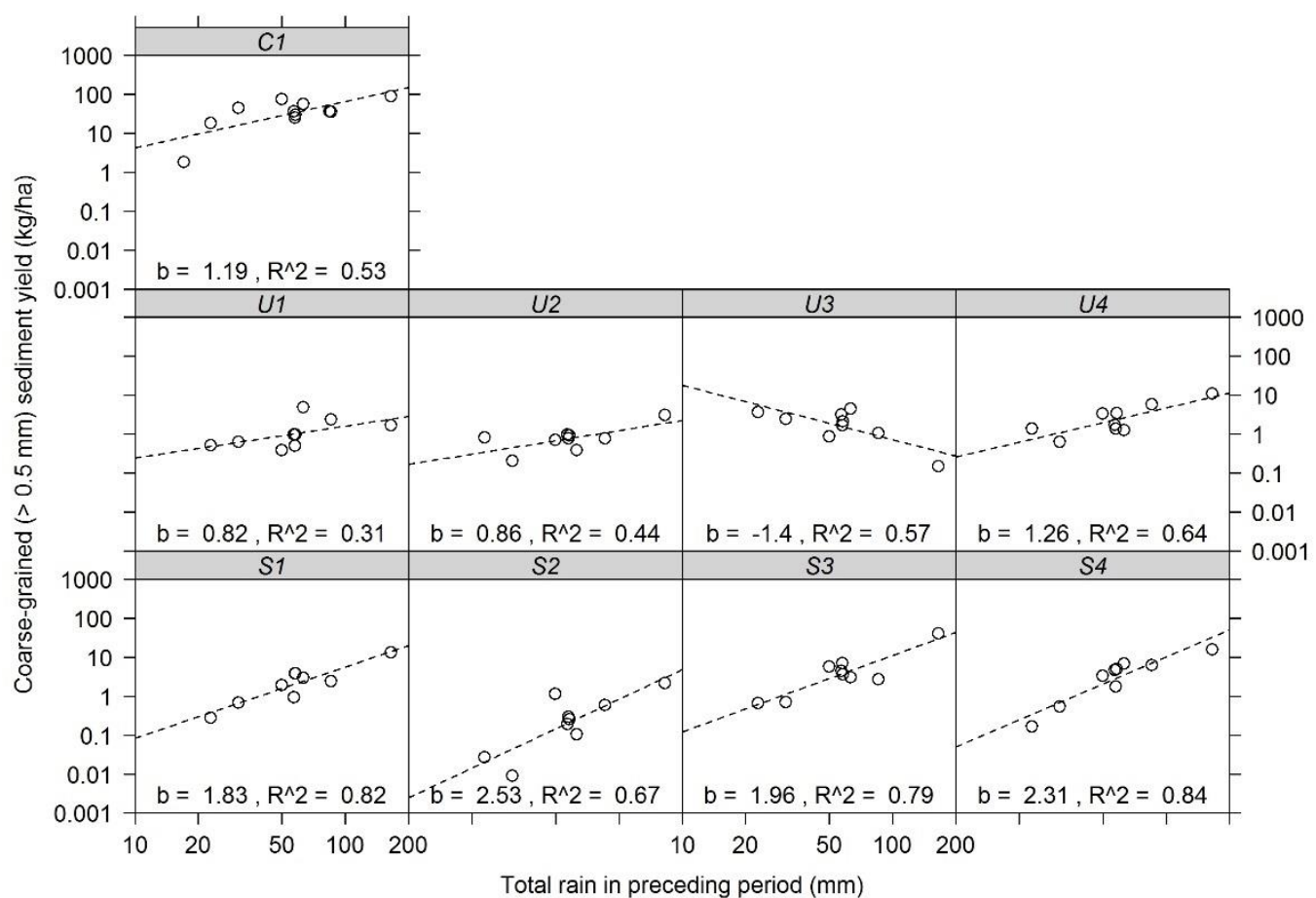

Relationship between coarse-grained $(>0.5 \mathrm{~mm})$ specific sediment yield and total rainfall for the period between sampling dates in each hillslope catchment. Fitted regression lines between the logs of coarse-grained sediment load and total rain are shown. $R^{\wedge} \mathbf{2}$ refers to the coefficient of determination and $b$ refers to the slope of the fitted log-log regression line (i.e. the exponent of the power function for untransformed data), for each catchment. See Figure 2 for location details. pervious areas (i.e. grass, mulch or gravel) were much higher than impervious surfaces, particularly for coarser size fractions (up to 10 times higher for $>5 \mathrm{~mm}$ material). Of the different types of pervious surfaces, gravel produced yields around nine times higher than grass or mulch, although this partitioning could only be undertaken with reasonable confidence for the total $>0.5 \mathrm{~mm}$ size class, not the coarser $(>2 \mathrm{~mm}$ ) sub-class. Areas disturbed by construction produced coarse-grained 
surfaces and 20 times higher than pervious surfaces). The construction yields were derived from a single catchment, so their likely range and confidence limits could not be estimated.

354 Table 3

Typical coarse-grained sediment supply rates (rounded to 2 significant figures) by

land cover.

\begin{tabular}{|c|c|c|c|c|}
\hline \multirow[t]{3}{*}{ Surface Type } & \multicolumn{4}{|c|}{ Estimated coarse-grained sediment supply rate $(\mathrm{kg} / \mathrm{ha} / \mathrm{yr})$} \\
\hline & \multicolumn{2}{|l|}{$>0.5 \mathrm{~mm}$} & \multicolumn{2}{|l|}{$>2 \mathrm{~mm}$} \\
\hline & Estimate & $95 \% \mathrm{CL}$ & Estimate & $95 \% \mathrm{CL}$ \\
\hline Impervious (non-roof) & 21 & $\pm 110 \%$ & 5.0 & $\pm 180 \%$ \\
\hline Grass/mulch/gravel & 140 & $\pm 51 \%$ & 48 & $\pm 44 \%$ \\
\hline Grass/mulch ${ }^{1}$ & 84 & $\pm 97 \%$ & & \\
\hline Gravel $^{1}$ & 780 & $\pm 95 \%$ & & \\
\hline Construction & 2,800 & - & 1,300 & - \\
\hline
\end{tabular}

Modelled sediment supply rates for typical urban and suburban catchments (Figure 10) indicate that total coarse-grained $(>0.5 \mathrm{~mm}$ ) hillslope sediment supply to suburban catchments is likely to be slightly higher than from urban catchments. The difference is likely to be greater for coarser sediment fractions (i.e. $>2 \mathrm{~mm}$ particles), which are supplied in very small quantities from impervious surfaces. Construction areas are likely to provide a large proportion of the sediment supply, even if construction covers only a small proportion of the catchment (i.e. $0.5 \%$ construction area adopted for this modelling). The contribution of construction is proportionally higher for coarser-grained materials. For typical suburban catchments (with low levels of construction), the coarse-grained hillslope sediment yield is provided mostly by grass/mulch surfaces (35\%) and construction areas (32\%), with smaller contributions from gravel (22\%) and impervious surfaces (12\%). 

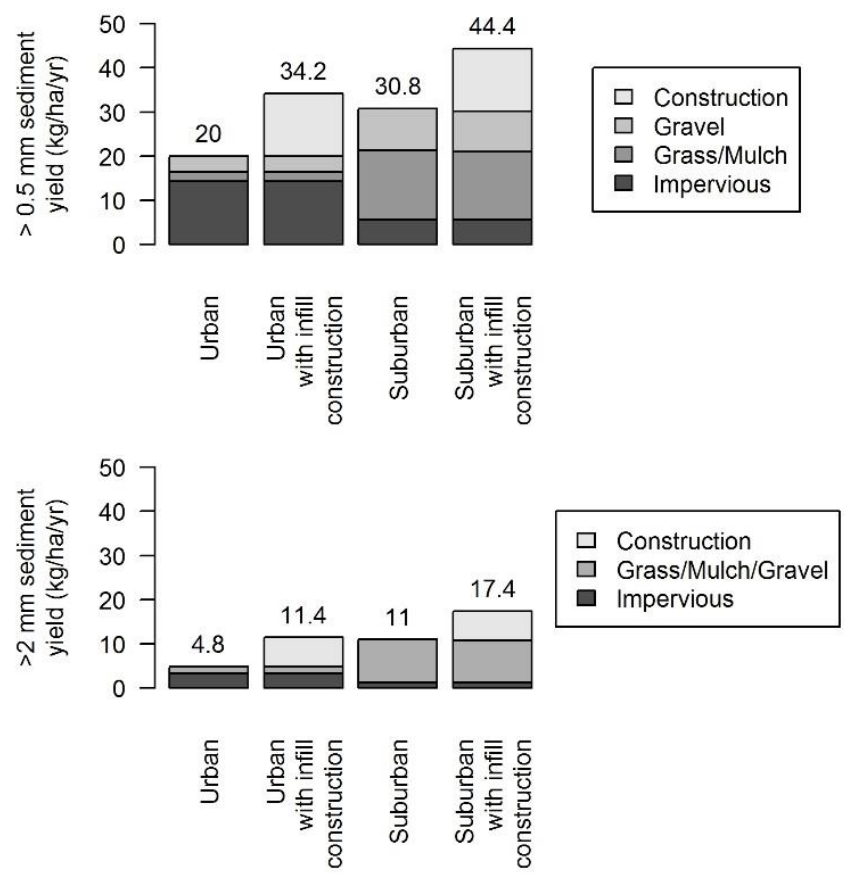

Modelled hillslope coarse-grained sediment yields for typical urban ( $97 \%$ total imperviousness) and suburban (50\% total imperviousness) areas, with and without typical levels of infill construction (0.5\%).

Measured hillslope coarse-grained sediment yields were higher for suburban than urban catchments, indicating that increased impervious surface area beyond typical suburban levels reduces hillslope sediment yield, as discussed by Wolman (1967). Despite this, impervious areas still provide appreciable yields of coarse-grained sediments, which are much higher than commonly considered. Impervious surfaces reduce sediment supply compared to mixed suburban catchments, but not necessarily below pre-urbanization conditions. Construction areas, by contrast, provide sediment yields many times higher than general urban or suburban areas. These high unit-area yields mean that infill construction activities can supply a large proportion of urban hillslope sediment supply, even with only small proportions of catchment area under construction. 
The size of particles delivered from hillslopes was also surprisingly large, up to $70 \mathrm{~mm}$. The majority of coarse-grained material was sand-sized $(0.5-2 \mathrm{~mm})$, but on average, over $30 \%$ was gravel-sized (> $2 \mathrm{~mm}$ ) in the suburban catchments, and around $45 \%$ in the catchment with construction. We would expect there to be some limitation to the size of particles that can be transported in urban overland flows, but that limit appears to be quite high compared to the natural bedload supply in this region, further highlighting the transport efficiency of urban drainage. Nearby comparable non-urban streams have fine gravel or gravel/sand beds (Russell et al., 2018) indicating that very coarse-grained sediment is naturally scarce. Non-fluvial processes acting on coarser particles in urban areas (e.g. vehicle or pedestrian traffic) could contribute to moving very coarse particles into stormwater drains.

This study is the first to demonstrate these results for coarse-grained sediment across a range of land cover types, so there is little published material for comparison. However, comparisons can be made by combining studies on total or suspended yield with studies on particle size distributions. The impervious surface coarse-grained yield derived in this study $(21 \mathrm{~kg} / \mathrm{ha} / \mathrm{yr})$ is around $5 \%$ of the typical suspended yield for highways, derived by Nelson and Booth (2002) from data from Mar et al. (1982) in Washington state. The coarse-grained $(>0.5 \mathrm{~mm})$ fraction of total sediment yield in road runoff can range from $2-40 \%$ (Kim and Sansalone, 2008), indicating that our estimate is within the bounds of existing observations.

401 The typical suburban coarse-grained hillslope supply estimated in this study ( $44 \mathrm{~kg} / \mathrm{ha} / \mathrm{yr}$ ) was lower than similar catchments in the United States, which is unsurprising given the geologically older, less active landscapes of the study area. For example, Smith and Wilcock (2015) derived a hillslope sediment yield for sand-sized and larger particles (excluding channel sources) of around $900 \mathrm{~kg} / \mathrm{ha} / \mathrm{yr}$ for two first-order suburban basins in the mid-Atlantic Piedmont. The fractions of coarser materials (e.g. $>0.5 \mathrm{~mm}$ fractions that could be directly compared with our findings) were not reported and could be much lower. The construction coarse-grained yield estimated in this study $(2,800 \mathrm{~kg} / \mathrm{ha} / \mathrm{yr})$ was broadly consistent with observations by Guy (1974) of a yield of 3,300 kg/ha/yr of sand-sized or coarser material ( $>0.063 \mathrm{~mm}$ ) from a fully disturbed construction area. 
The scarcity of published information on coarse-grained sediment supply from urban areas highlights a need for future research to investigate the urban sediment regime in different climatic, geological and urban design settings to tease out global responses and trends. Better understanding the effects of local conditions could lead to more informed urban design that is sensitive to waterway processes.

\section{Processes contributing to spatial and temporal variability}

The high spatial and temporal variability of sediment supply processes can make it difficult to estimate typical or average yields from short-term monitoring at a few locations (Dietrich and Dunne, 1978). Spatial and temporal variability were assessed to evaluate the validity of our extrapolation of measured loads to annual yields, and to typical yields for surface types.

Spatial variability depends on variability in static or average attributes like source characteristics, the spatial arrangement of land cover, and levels of human intervention and management. Yields and particle size distributions were more variable for suburban than urban catchments, which may reflect the higher complexity of surfaces in the suburban catchments. The urban catchments were relatively homogeneous, with mostly impervious surface cover with some peripheral grass, gravel or mulch land cover. The suburban catchments, however, were a mosaic of different surface types (see Figure 5), with roads, footpath and driveways forming a conduit between pervious sources (e.g. gravel landscaping, garden beds, bare soil patches) and the drainage network.

Based on observations within the monitored hillslope catchments, it appears that gravel surfaces are important, yet highly variable sediment sources. A typical rate of supply was difficult to estimate, partly due to their low coverage compared to other land cover types in the catchments, and partly due to variability in types and sizes of gravel, rates of packing and compaction, vehicle/pedestrian traffic rates, replenishment activities, and connectivity. Patterns of street sweeping, which is highly effective at removing large particles (Sartor and Gaboury, 1984) could also contribute to the variability of coarse sediment supply. Street sweeping may contribute to higher average sediment yields from suburban catchments, which are cleaned less often than urban catchments, and might be a reason for 
the low yield observed in catchment $\mathrm{U} 1$, which is in a major shopping strip and is swept six days per week (City of Monash, 2018).

Temporal variability depends on the variable responses of different catchments to rainfall, as well as specific disturbance or management events. Monthly sediment supply rates were strongly driven by total rainfall, especially for the suburban catchments, suggesting extrapolation to an annual yield using the total annual rainfall is valid. The strength of this relationship was greater for the suburban than urban catchments, and in general, greater for catchments with higher total yields. The exponent of the non-linear relationship was also greater for the suburban than urban catchments, with values close to 1 (near-linear) for the urban catchments but closer to 2 for the suburban catchments. We interpret lower yields (given similar hydraulic conditions across the catchments), lower exponents and weaker relationships between sediment load and rainfall as indicators of lower erodibility and supplylimited conditions.

In supply-limited systems, the capacity of transport processes exceeds the supply of loose material to the land surface (Kirkby, 1971), meaning that hydraulic factors cannot fully explain sediment yield, and episodic sediment-supply processes must also be considered (Imaizumi and Sidle, 2007). In the urban context, episodic processes like street sweeping (sediment removal) and landscaping and excavation (sediment supply) mean that sometimes when a rainstorm occurs there will be plentiful loose material available for transport while at other times erodible material will be scarce. Catchments with more sediment sources available (i.e. suburban areas) are more erodible and thus, rainfall and runoff can more easily and consistently detach and transport material, making sediment loads higher and more strongly associated with rainfall. There was no evidence of loads tapering off to a plateau with larger rainfall events (except in U3), indicating that source exhaustion does not occur even in the largest measured events (equivalent to a six-year recurrence interval event). Supply limitations are therefore associated with lower erodibility of land cover surfaces (such as impervious surfaces) rather than exhaustion of sources during events. 
The catchment with construction (C1) had a weaker relationship between load and rainfall than the other suburban catchments, despite its high yield and high source availability. This suggests that drivers other than rainfall (e.g. construction stage or practices) have a significant role in the temporal variability of sediment supply from construction areas. Construction activities vary greatly over the life of a construction project and specific disturbance events like cut, fill, spills, erosion control implementation or failure, and stockpiling of building materials can produce episodic sediment supply processes (Harbor, 1999; Kaufman, 2000). This study followed the construction site in C1 from vacant site to completion. The decline in sediment yield in the final three months of the study reflects the cessation of earthmoving, completion of landscaping and removal of stockpiles from the site during that period.

The negative trend between rainfall and sediment load at U3 is relatively strong, but opposite to the expected direction. Two possible explanations exist: i) either the variability is completely due to nonrainfall-related factors and the trend is coincidental; or ii) the shape and placement of the trap produced a scouring and resuspension effect in high runoff conditions. The latter explanation appeared to be a factor in the very low load observed on 11 December 2017 (after the highest rainfall event), when some coarse sediment was found at the bottom of the stormwater pit, but very little in the trap itself. If that point is removed, the trend between load and rainfall disappears for that site (Rsquared $=0.16$ ). The general downwards trend over the whole sampling period (Figure 8 ) indicates that non-climatic factors were also at play, limiting the sediment availability as time progressed. The sediment load for this catchment was supplied mainly by a narrow strip of gravel surfacing, which was not topped up during the sampling period and was visibly depleted over the study period. It is likely that sediment supply from the gravel surface was exhausted over time as the surface lowered and became disconnected. 
The modelled hillslope coarse-grained sediment yields indicate that supply from impervious surfaces is the dominant source in highly-urbanized catchments, particularly for sand-sized sediments. Sediments can be supplied either from breakdown of the impervious material itself, or from foreign material deposited onto the impervious surface by vehicle or foot traffic. Atmospheric deposition by rain or wind is also an important process for finer sediments (Sutherland and Tolosa, 2000), but unlikely to be important for coarse-grained particles, which require higher-energy storms for transport.

For suburban catchments, the contribution of pervious surfaces is dominant, particularly grassed or mulched surfaces, which are prevalent, but also gravel surfaces, which are present in lower proportions but produce relatively more sediment per area. Gravel surfaces are usually replenished as they erode, providing essentially unlimited sediment supply over time. While well-grassed or wellmulched surfaces are unlikely to produce much coarse-grained sediment, there are always variations in ground cover due to shading of grass, disturbance by traffic or gardening activities, or wash-off of mulch toppings. It appears likely that these disturbed or bare patches in ground cover can provide most of the sediment supply, especially if they are well-connected to the drainage network. These examples highlight the geomorphic effectiveness of active urban land management by authorities and private landholders. Connected impervious surfaces form the main conduit between pervious sources and the drainage network. While they provide a minor proportion of the coarse-grained sediment production in suburban areas (e.g. $12 \%$ in typical suburban catchments with low levels of infill construction; Figure 10), they play an important role in sediment delivery to the drainage network. provide most of the sediment supply. Modelling suggests that in typical suburban catchments, less 
the coarse-grained sediment. Construction activities are estimated to contribute $32 \%$ of the hillslope coarse-grained sediment supply from typical suburban catchments, where the effectively-drained construction areas cover only $0.5 \%$ of the catchment. Similar observations of small construction areas having a disproportionately large impact were made by Leopold and Dunne (1978). Consequently, urban sediment supply is very sensitive to small changes in key sources. An urban renewal phase would produce a construction boom that could dominate the sediment supply, even if it only affected a few per cent of the catchment area. A move towards gravel surfacing in roadsides, parks and gardens could produce similarly large increases in sediment supply.

Sediment fingerprinting studies can provide information on the contribution of different sources to urban sediment yields for comparison with our results. Devereux et al. (2010) broke down sediment sources in a mostly urban catchment into upland, streambank and street contributions, finding that streets contributed 13\% and uplands (including urban hillslopes) 30\%. Franz et al. (2014) undertook sediment fingerprinting on a finer scale for a small mixed-use catchment in Brasilia, including construction sites, paved roads, unpaved roads and residential areas. Urban sediments dominated the sediment contribution (78\%), despite making up only $38 \%$ of the catchment area. Of the urban sediments, residential areas were the largest contributor (42\%), followed by construction sites (20\%), unpaved roads/roadside ditches (12\%) and paved roads/highways $(4 \%)$. While these studies targeted finer sediments than ours, the relative contributions of different land cover types was similar, indicating that residential areas likely produce higher unit yields and contribute more sediment than highly impervious areas, and that construction areas can contribute significantly to the suburban sediment budget across a range of contexts.

\subsection{Sediment connectivity of urban hillslopes}

The observation that small sources which are well-connected to drainage can dominate suburban sediment supply points to the importance of connectivity as a driver of hillslope sediment supply, and a key factor in its spatial variability. Sources which are cut off from effective sediment delivery by 
buildings, fences or depressions (termed 'ineffective' areas) will not contribute to the overall catchment sediment supply. Instead, any locally-mobilised sediment in ineffective areas will be stored locally and likely overgrown with grass or reworked in gardening activities.

We conceptualised the connectivity of the urban hillslope catchment using a sediment cascade (Figure 1) and a sediment (dis)connectivity framework (Fryirs et al., 2007a), identifying areas disconnected from the urban drainage system by 'buffers' (e.g. fences, walls, sinks) as 'ineffective'. The ineffective area was highly spatially variable, ranging from zero to $78 \%$ of the pervious area for suburban areas. The average connectivity of $40 \%$ of the pervious area was used to model hillslope sediment supply for 'typical' catchments. The actual average connectivity in suburban areas may be quite different to the detailed hillslope catchments, representing a large source of uncertainty for our estimates. A widespread assessment of sediment (dis)connectivity would be ideal, but there are significant challenges in implementing an automated GIS-based method as per Fryirs et al. (2007b), given the complexity of the urban land surface and underground drainage system, and the likely importance of distributed, small scale (dis)connectivity elements. Detailed mapping of impervious areas, buildings and fences would be required across the catchment, along with a highly detailed, hydrologicallyenforced digital elevation model (DEM). Hydrological enforcement must follow the artificial and dense drainage patterns of the urban surface (gutters and pits) rather than the natural slope of the catchment. An alternative method would be to apply an 'attenuated' source area method (Walsh and Kunapo, 2009) whereby the sediment-supply signal of a source area could be attenuated with distance from a stormwater drain using a mathematical function. For any automated assessment, the development and maintenance of high-quality, detailed land cover and drainage GIS layers is critical. in the present study. Sediment (dis)connectivity elements are not fixed, but have the capacity to be breached, depending on the magnitude of disturbance events (Fryirs, 2013). Thus, sediment 557 connectivity in urban hillslopes can vary with rainfall intensity and duration, similarly to the 'variable 558 source area' concept in hydrology. Given that sediment delivery depends on runoff, sediment 
connectivity must be strongly influenced by hydrological connectivity (Bracken and Croke, 2007). The impervious areas produce runoff and can deliver sediment in all but the smallest rainfall events, whereas the pervious areas only contribute runoff and sediment in some events depending on the event magnitude and the presence and strength of buffers.

We also note that rainfall and runoff are not the only detachment and transport processes acting on sediments. Mechanical and biological processes such as vehicle and pedestrian traffic are likely very important in moving coarse particles towards concentrated flow paths (Sack and Da Luz, 2003). For example, sediment spilled onto a road between rainfall events is likely to be reworked significantly by vehicle traffic before it is subject to fluvial processes. Similarly, vehicles on gravel driveways and pedestrians on gravel paths are important agents in moving particles towards impervious surfaces and hence towards drains. Therefore, connectivity of these processes (e.g. location of roads and paths relative to sources, and traffic rates) play a part in the overall sediment connectivity of urban hillslopes.

Notwithstanding these complexities, urbanization consistently and dramatically increases hydrological, and therefore sediment connectivity. In the study area the drainage density is increased more than 20-fold over likely natural conditions (see Section 2), effectively reducing the average distance a particle must travel from a point on the hillslope to the drainage network (whether by fluvial or non-fluvial processes) to a fraction of its pre-urbanization value.

A coarse-grained hillslope sediment budget was developed for a 'typical suburban' catchment with infill construction from the results of this study (Figure 11). We used a conceptual sediment cascade

580 (Figure 1) to guide the development of this budget. This study only provides the data to conceptualise 581 the hillslope domain of the cascade, therefore the downstream boundary of the sediment budget was 582 set at the interface between the hillslope and the stormwater network. We developed reasonable estimates for hillslope supply to stormwater network (partitioned by land cover), while the other 
components (total hillslope sources, storage in buffers, export by street sweeping) were estimated to order-of-magnitude level using typical connectivity estimates and council-provided street sweeping quantities.

Estimates of hillslope processes indicate that only a fraction of eroded sediment reaches the stormwater network. On pervious surfaces, much of the eroded sediment is likely captured and stored behind fences and in sinks and low-gradient areas (buffers), never leaving pervious hillslopes. We assumed that $60 \%$ of pervious hillslope areas were disconnected by buffers, based on the average connectivity in the study catchments. The total quantity of coarse-grained sediment eroded from hillslopes was estimated to be $110-420 \mathrm{~kg} / \mathrm{ha} / \mathrm{yr}$, of which $55 \%$ was stored in buffers. Of the sediment that reaches impervious surfaces (especially roads), a portion is removed by street sweeping, estimated for the study area to be around $7-150 \mathrm{~kg} / \mathrm{ha} / \mathrm{yr}$ (6-36\% of hillslope erosion). This was based on the local council reporting that they remove around 3,000 tonnes per year of material from their $81 \mathrm{~km}^{2}$ area (City of Monash, 2018), and on findings that the coarse-grained (>0.5 $\mathrm{mm}$ ) fraction of total sediment yield in road runoff can range from 2-40\% (Kim and Sansalone, 2008). The remainder (10-40\% of hillslope erosion; $44 \mathrm{~kg} / \mathrm{ha} / \mathrm{yr})$ is delivered to stormwater drains.

Future work to extend this conceptualisation of the urban sediment budget beyond hillslopes to include the stormwater network and channels will need to consider a range of further (dis)connectivity elements (i.e. barriers and blankets; Fryirs et al. (2007a)). Sediment stores in the underground network, behind weirs, in constructed basins, on floodplains and in channels are expected to be important in a catchment-scale budget, as well as material exported from these stores. 


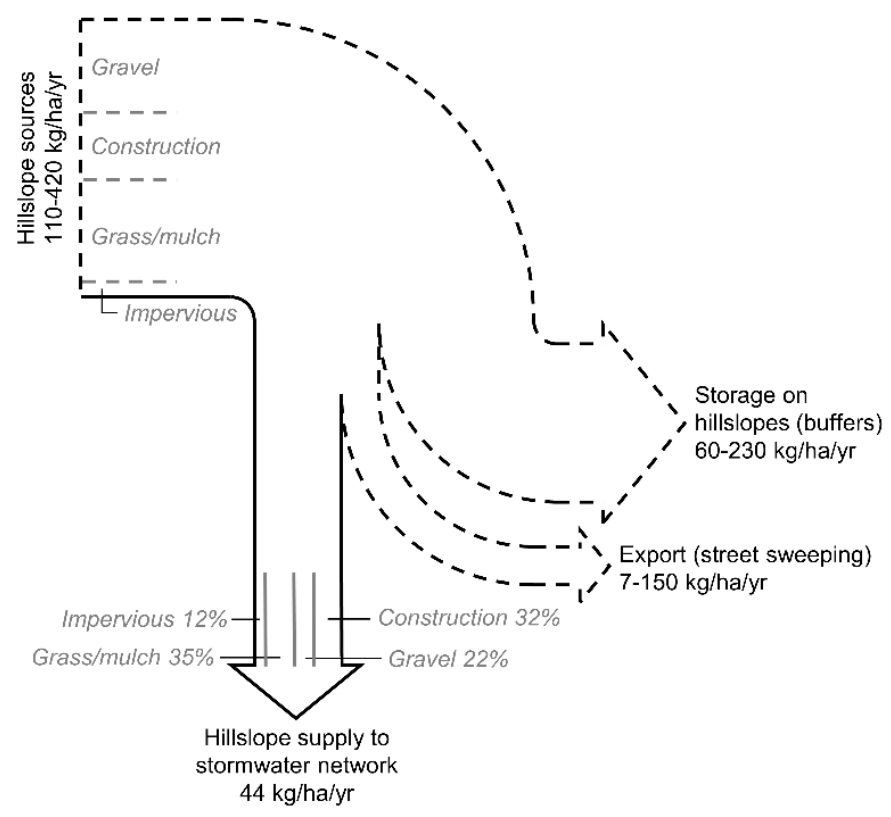

Sediment budget schematic for hillslope delivery of coarse-grained sediment. Solid order-of-magnitude level.

610 The value of better understanding the coarse-grained sediment supply regime from an urban

611 catchment is in predicting stream response and trajectory. We can extrapolate our findings on the contributions of different land cover types and the importance of drainage connection to develop a conceptual model of the response of hillslope coarse-grained sediment supply to urbanization intensity (Figure 12). This conceptual model is intended for comparison of catchments with different levels of urbanization with stable land cover and low levels of ongoing construction activity. 


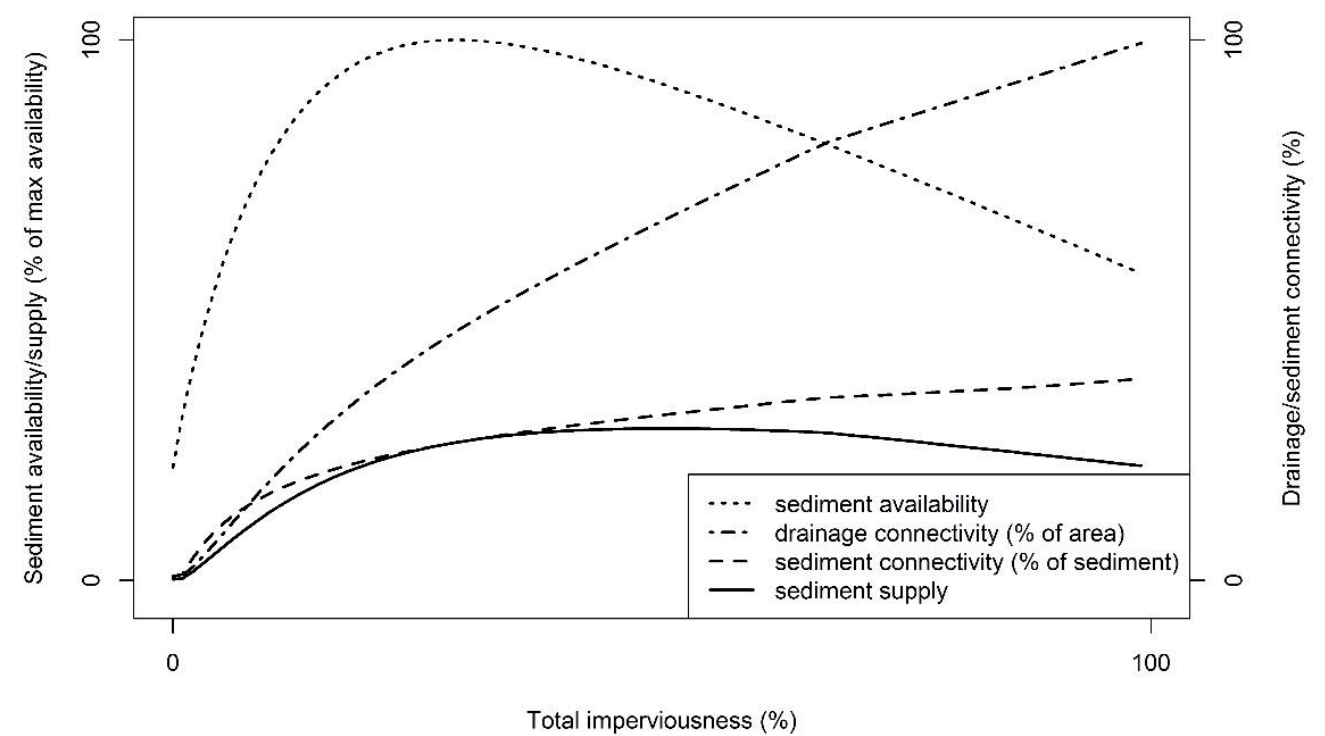

Figure 12 Conceptual model of the response of coarse-grained sediment availability, drainage connectivity (\% of area with sediment connectivity to drainage network), sediment connectivity (\% of total available sediment connected to drainage network), and coarse-grained sediment supply to urbanization intensity (represented by total imperviousness), for environments with low background sediment yield and traditional stormwater drainage, based on drainage connectivity and sediment supply characteristics of eastern Melbourne.

Coarse-grained sediment supply is conceptualised as the product of source availability (the amount of sediment readily available in the catchment) and source connectivity (the proportion of those sources that are connected to the drainage network over relevant time scales). Availability of sediment first increases with urbanization from low background levels as earthmoving activities and anthropogenic sources (gravel surfacing, gardening, landscaping, construction) expand. Sediment availability then reaches a maximum and declines at higher urbanization intensities as pervious sources are converted to impervious surfaces, until the only remaining sources are impervious surfaces and infill/renewal construction. Meanwhile, source connectivity increases with urbanization as directly connected impervious area and stormwater drainage density increase. In natural catchments, hillslope coarsegrained sediment supply is low because of low connectivity. In suburban catchments supply reaches 
a maximum, where there are enough pervious sources available, and connectivity is high enough to deliver a large proportion of the available sediment to the stormwater network. At higher levels of urbanization, sources become scarcer, causing sediment supply to decline despite increasing levels of connectivity.

The form of the curves is based on connectivity and sediment supply estimates from eastern Melbourne, and is generally valid for areas with low background sediment availability and connectivity, and high urban drainage connectivity. The conceptual model illustrates how, under these circumstances, sediment supply can increase with imperviousness even though sediment production from impervious surfaces is low. In our study area, the total hillslope sediment supply to the stormwater network under fully urbanized conditions (44 kg/ha/ $\mathrm{yr}$ ) is much higher than the background coarse-grained sediment supply from similar, forested catchments (estimated to be 0.01$0.6 \mathrm{~kg} / \mathrm{ha} / \mathrm{yr}$ by Russell et al. (2018)). In more active landscapes with higher background sediment supply rates, the curve forms will vary from those shown here, and sediment supply may remain relatively stable or even decline from background to suburban to fully urban conditions (e.g. Southern California; Warrick and Rubin (2007), Brownlie and Taylor (1981)).

\section{Implications for urban stream channel recovery}

The plateau-shaped response curve of coarse-grained sediment supply to increasing urbanization is in stark contrast to sediment transport capacity, which keeps increasing with effective imperviousness, leading to greater and greater sediment supply limitation. It is this sediment limitation that, coupled with dramatically increased transport capacity, contributes to bed sediment scour and channel enlargement in streams with urbanized catchments. The model allows us to better understand the effect of reducing the hydrological connectivity between impervious surfaces and the stream, to avoid impacts from the urban flow regime (Walsh et al., 2015; Walsh et al., 2005a). A reduction in drainage connectivity at constant total imperviousness would keep source availability constant while reducing source connectivity. Without sediment bypass or replenishment arrangements in place, coarse- 

stream.

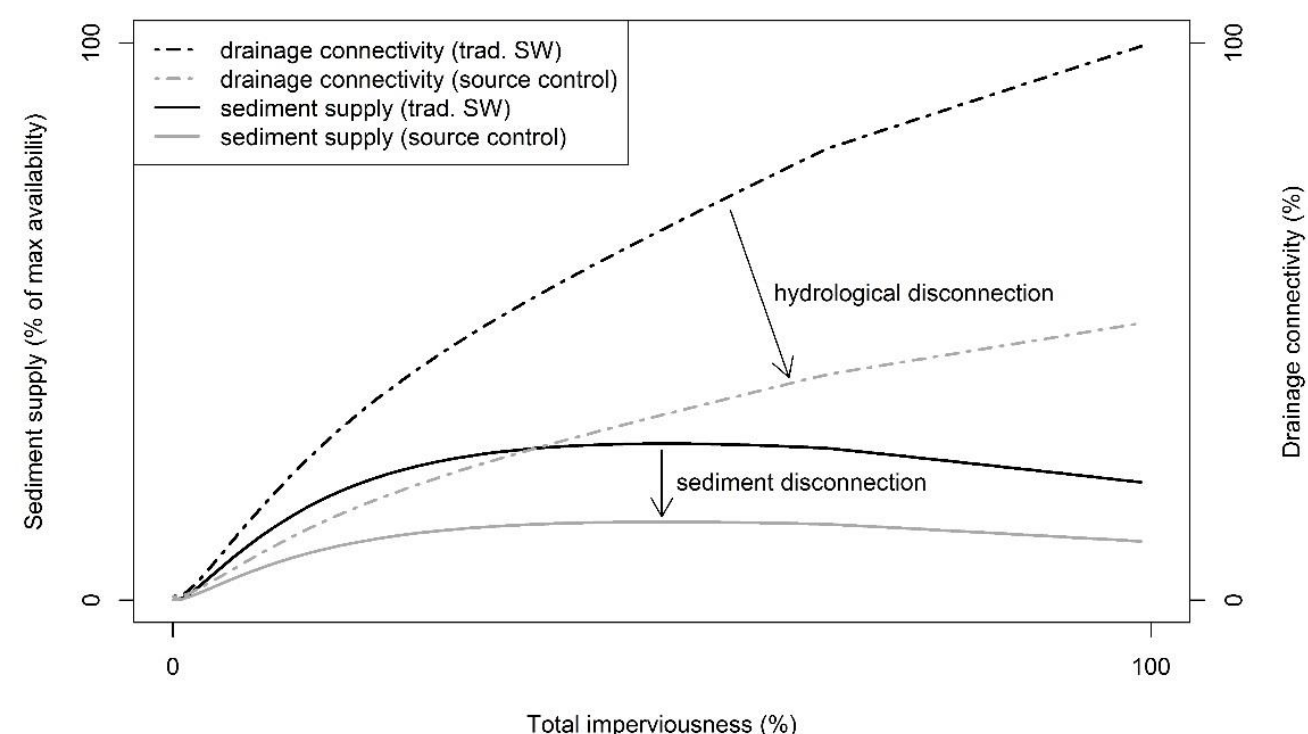

663

Given this context, sediment supply limitations are likely to remain a constraint to stream channel

grained sediment supply would be expected to decrease approximately linearly with drainage connectivity (Figure 13), favouring ongoing supply-limited sediment transport conditions in the

Figure 13 Conceptual model of the response of drainage connectivity (\% of area with sediment connectivity to drainage network) and coarse-grained sediment supply to urbanization intensity (represented by total imperviousness), under both traditional stormwater drainage ('trad. SW'), and hydrological disconnection of $50 \%$ of urban surfaces using source control measures ('source control'). The effect of hydrological disconnection is to disconnect sediment sources and reduce sediment supply at the same time as reducing flows. The model is based on drainage connectivity and sediment supply characteristics of eastern Melbourne.

recovery, even under better hydrological management regimes. It seems likely, therefore, that source control measures will need to be paired with coarse-grained sediment bypass or specific replenishment arrangements to allow stream substrates and disturbance regimes to return to more natural conditions (Stein et al., 2012). A major design challenge exists in developing such bypass arrangements while keeping harmful and potentially contaminated urban fine-grained sediment out 
of streams (Taylor and Owens, 2009). Given that so much of the sediment supply is from non-native sources (gravel toppings, impervious surfaces, construction materials), a further question around the ecological value of imported material needs to be answered. Nonetheless, we believe that providing persistent and resilient substrates which are able to improve channel complexity and physical habitat will go a long way towards ecological restoration in urban streams. A detailed assessment of the effect of urbanization on sediment transport capacity, which is a much more complex process than represented here (Wainwright et al., 2015), would help us to define requirements for urban source control measures or sediment replenishment, and stream management generally.

\section{CONCLUSION}

Conclusions can be drawn against the key questions of the paper as follows:

1. Typical coarse-grained (>0.5 mm) sediment supply rates from urban hillslopes were substantially higher than previously thought. Typical rates of coarse-grained sediment supply were $21 \mathrm{~kg} / \mathrm{ha} / \mathrm{yr}$ from connected ground-level impervious surfaces, $84 \mathrm{~kg} / \mathrm{ha} / \mathrm{yr}$ from connected grass/mulch surfaces, $780 \mathrm{~kg} / \mathrm{ha} / \mathrm{yr}$ from connected gravel surfaces, and 2,800 $\mathrm{kg} / \mathrm{ha} / \mathrm{yr}$ from connected construction areas. Integrating these unit supply rates over typical land-cover and connectivity arrangements of suburban and highly urban catchments resulted in coarse-grained sediment supply estimates of $44 \mathrm{~kg} / \mathrm{ha} / \mathrm{yr}$ for suburban areas and 34 $\mathrm{kg} / \mathrm{ha} / \mathrm{yr}$ for fully urban areas.

2. In typical suburban catchments, the key sources of coarse-grained sediment were grassed and mulched surfaces (35\% of supply) and small-scale construction areas (32\%). Gravel surfaces also provided appreciable amounts of sediment (22\%) despite covering only a small proportion of the catchment. In typical urban catchments, most of the coarse-grained sediment was supplied by impervious surfaces (42\%) and small-scale construction areas (42\%). 
3. Connectivity between sediment sources and the drainage network is high in suburban and urban catchments, and is a key driver of coarse-grained sediment supply. Impervious surfaces, as well as producing appreciable amounts of coarse-grained sediment themselves, provide conduits in the suburban land-cover mosaic for connection of small, distributed sources to the stormwater network.

4. A conceptual model of the response of hillslope coarse-grained sediment supply to different levels of urbanization indicated that hillslope coarse-grained sediment supply increases with urbanization from natural to suburban conditions as connectivity increases, then declines with higher levels of urbanization as sources become scarcer. While sediment supply is increased in urban catchments compared to background levels, it appears likely that transport capacity increases to a greater degree, causing severely supply-limited conditions which drive streambed degradation and channel enlargement downstream. Attempts to address the urban flow regime by reducing hydrological connectivity are likely to also reduce sediment supply, maintaining supply-limited conditions and constraining channel recovery potential. To improve the chances of success of such interventions, and the success of sustainable stream management, consideration should be given to coarse-grained sediment bypass or replenishment arrangements.

\section{ACKNOWLEDGEMENTS}

This work was funded by an Australian Government Research Training Program Scholarship and the Melbourne Waterway Research Practice Partnership (http://mwrpp.org). Fletcher was supported by the Australian Research Council (FT100100144) during part of this study. The funding sources had no direct involvement in the study.

The study was made possible by the assistance of many people, including: Rob James, for assistance in installing equipment; numerous field assistants, especially Tony Lovell; and Joshphar (Jasper) 
Kunapo of Grace Detailed-GIS Services and Chris Walsh, for land cover mapping; and Melbourne Water for providing drainage layers and LiDAR data. The comments of three anonymous reviewers greatly improved this paper.

Allison R., Walker T., Chiew F., O'Neill I., McMahon T., 1998. From roads to rivers: gross pollutant removal from urban waterways, Cooperative Research Centre for Catchment Hydrology.

ASRIS, 2018. ASRIS - Australian Soil Resource Information System. Available at: http://www.asris.csiro.au.

Booth D.B., 1991. Urbanization and the natural drainage system--impacts, solutions, and prognoses. The Northwest Environmental Journal 7: 93-118

Bracken L., Croke J., 2007. The concept of hydrological connectivity and its contribution to

Burnham K.P., Anderson D.R., 2003. Model selection and multimodel inference: a practical Bureau of Meteorology, 2018. Australian Daily Rainfall Gridded Data. Available at: http://www.bom.gov.au/climate/how/newproducts/IDCdrgrids.shtml.

approach:

Springer
$\&$

Business 
Burns M.J., Walsh C.J., Fletcher T.D., Ladson A.R., Hatt B.E., 2015. A landscape measure of urban stormwater runoff effects is a better predictor of stream condition than a suite of hydrologic factors. Ecohydrology 8: 160-171.https://doi.org/10.1002/eco.1497

Chin A., 2006. Urban transformation of river landscapes in a global context. Geomorphology 79: 460487.http://dx.doi.org/10.1016/j.geomorph.2006.06.033

City of Monash, Street Cleaning. Available at: https://www.monash.vic.gov.au/Services/Rubbish-Recycling/Keeping-Monash-Clean/StreetCleaning.

Department of Environment Land Water \& Planning, 2016. Housing Development Data 2014. Available at: https://www.data.vic.gov.au/data/dataset/project-layer-depicting-housing-activity-overthe-years-from-2005-and-2014.

Devereux O.H., Prestegaard K.L., Needelman B.A., Gellis A.C., 2010. Suspended-sediment sources in an urban watershed, Northeast Branch Anacostia River, Maryland. Hydrological Processes 24: 1391-1403.https://doi.org/10.1002/hyp.7604

Dietrich W., Dunne T., 1978. Sediment budget for a small catchment in a mountainous terrain. Zeitschrift für Geomorphologie Supplementband 29: 191-206

Finkenbine J., Atwater J., Mavinic D., 2000. Stream Health After Urbanization. Journal of the American Water Resources Association 36: 1149-1160.https://doi.org/10.1111/j.17521688.2000.tb05717.x

Fletcher T., Andrieu H., Hamel P., 2013. Understanding, management and modelling of urban hydrology and its consequences for receiving waters: A state of the art. Advances in Water Resources 51: 261-279.https://doi.org/10.1016/j.advwatres.2012.09.001

Franz C., Makeschin F., Weiß H., Lorz C., 2014. Sediments in urban river basins: Identification of sediment sources within the Lago Paranoa catchment, Brasilia DF, Brazil-using the fingerprint approach. Science of the Total Environment 466: 513523.https://doi.org/10.1016/j.scitotenv.2013.07.056 
Fryirs K., 2013. (Dis) Connectivity in catchment sediment cascades: a fresh look the sediment delivery problem. Earth Surface Processes and Landforms 38: 3046.https://doi.org/10.1002/esp.3242

Fryirs K., Brierley G., Preston N., Kasai M., 2007a. Buffers, barriers and blankets: The (dis)connectivity of catchment-scale sediment cascades. Catena 70 : 4967.https://doi.org/10.1016/j.catena.2006.07.007

Fryirs K.A., Brierley G.J., Preston N.J., Spencer J., 2007b. Catchment-scale (dis) connectivity in sediment flux in the upper Hunter catchment, New South Wales, Australia. Geomorphology 84: 297316.https://doi.org/10.1016/i.geomorph.2006.01.044

Gellis A.C., Myers M.K., Noe G.B., Hupp C.R., Schenk E.R., Myers L., 2017. Storms, channel changes, and a sediment budget for an urban-suburban stream, Difficult Run, Virginia, USA. Geomorphology 278: 128-148.http://dx.doi.org/10.1016/j.geomorph.2016.10.031

Gurnell A., Lee M., Souch C., 2007. Urban rivers: hydrology, geomorphology, ecology and opportunities for change. Geography Compass 1: 1118-1137.https://doi.org/10.1111/j.17498198.2007.00058.x

Guy H.P., 1974. Remote sensing techniques for evaluation of urban erosion and sedimentation. Effects of Man on the Interface of the Hydrological Cycle with the Physical Environment [Proceedings of the Paris Symposium, September 1974]. IAHS Pub. no. 113, pp. 145-149

Harbor J., 1999. Engineering geomorphology at the cutting edge of land disturbance: erosion and sediment control on construction sites. Geomorphology 31: 247263.https://doi.org/10.1016/S0169-555X(99)00107-5

Hatt B.E., Fletcher T.D., Walsh C.J., Taylor S.L., 2004. The influence of urban density and drainage infrastructure on the concentrations and loads of pollutants in small streams. Environmental Management 34: 112-124 
Hawley R.J., MacMannis K.R., Wooten M.S., 2013. Bed coarsening, riffle shortening, and channel enlargement in urbanizing watersheds, northern Kentucky, USA. Geomorphology 201: 111126.http://dx.doi.org/10.1016/j.geomorph.2013.06.013

Hawley R.J., Vietz G.J., 2016. Addressing the urban stream disturbance regime. Freshwater Science 35.https://doi.org/10.1086/684647

Houshmand A., Vietz G.J., Hatt B.E., 2014. Improving Urban Stream Condition by Redirecting Sediments: A Review of Associated Contaminants. In: Vietz G.J., Rutherfurd I.D., Hughes R.M., editors. Proceedings of the 7th Australian Stream Management conference, Townsville, Australia, pp. 549-557

Imaizumi F., Sidle R.C., 2007. Linkage of sediment supply and transport processes in Miyagawa Dam catchment, Japan. Journal of Geophysical Research: Earth Surface 112: n/an/a.https://doi.org/10.1029/2006JF000495

Kaufman M.M., 2000. Erosion control at construction sites: the science-policy gap. Environmental Management 26: 89-97.https://doi.org/10.1007/s002670010073

Kim J.-Y., Sansalone J.J., 2008. Event-based size distributions of particulate matter transported during $\begin{array}{lllll}\text { urban } & \text { 27ainfall-runoff }\end{array}$ 2768.https://doi.org/10.1016/j.watres.2008.02.005

Kirkby M., 1971. Hillslope process-response models based on the continuity equation. Inst. Br. Geogr. Spec. Publ 3: 5-30

Lane E.W., 1955. The importance of fluvial morphology in hydraulic engineering. Proceedings (American Society of Civil Engineers) 81

Leopold L.B., Dunne T., 1978. Water in environmental planning. New York

Mackin J.H., 1948. Concept of the graded river. Geological Society of America Bulletin 59: 463-512

Mar B., Horner R., Ferguson J., Spyridakis D., Welch E., 1982. Summary - Highway Runoff Water Quality Study, 1977-1982, Washington State Dept. of Transportation, Olympia, WA. 
Meyer J.L., Paul M.J., Taulbee W.K., 2005. Stream ecosystem function in urbanizing landscapes. Journal of the North American Benthological Society 24: 602-612.https://doi.org/10.1899/04-021.1

Nelson E.J., Booth D.B., 2002. Sediment sources in an urbanizing, mixed land-use watershed. Journal of Hydrology 264: 51-68

Paul M.J., Meyer J.L., 2001. Streams in the urban landscape. Annual Review of Ecology and Systematics 32: 333-365.https://doi.org/10.1146/annurev.ecolsys.32.081501.114040

Rowan J.N., Ransome S.W., Russell L.D., Rees D.B., 2000. Land Systems of Victoria (3rd ed.), Centre for Land Protection Research.

Russell K.L., Vietz G.J., Fletcher T.D., 2017. Global sediment yields from urban and urbanizing $\begin{array}{llll}\text { watersheds. } & \text { Earth-Science } & \text { 73- }\end{array}$ 80.https://doi.org/10.1016/i.earscirev.2017.04.001

Russell K.L., Vietz G.J., Fletcher T.D., 2018. Urban catchment runoff increases bedload sediment yield and particle size in stream channels. Anthropocene 23: 53-66. https://doi.org/10.1016/j.ancene.2018.09.001

Sack D., Da Luz S., 2003. Sediment flux and compaction trends on off-road vehicle (ORV) and other trails in an Appalachian forest setting. Physical Geography 24: 536-554

Sartor J.D., Gaboury D.R., 1984. Street sweeping as a water pollution control measure: Lessons learned over the past ten years. Science of the Total Environment 33: 171183.https://doi.org/10.1016/0048-9697(84)90391-7

Smith R.F., Hawley R.J., Neale M.W., Vietz G.J., Diaz-Pascacio E., Herrmann J., et al., 2016. Urban stream renovation: incorporating societal objectives to achieve ecological improvements. Freshwater Science 35: 364-379.https://doi.org/10.1086/685096

Smith S., Belmont P., Wilcock P.R., 2011. Closing the gap between watershed modeling, sediment budgeting, and stream restoration. In: Simon A., Bennett S.J., Castro J.M., editors. Stream Restoration in Dynamic Fluvial Systems: Scientific Approaches, Analyses, and Tools, 

317.https://doi.org/10.1029/2011GM001085

850

851

852

853

854

855

856

857

858

859

860

861

862

863

864

865

866

867

868

869

870

871

Smith S., Wilcock P., 2015. Upland sediment supply and its relation to watershed sediment delivery in the contemporary mid-Atlantic Piedmont (USA). Geomorphology 232: 3346.https://doi.org/10.1016/i.geomorph.2014.12.036

Stein E.D., Federico F., Booth D.B., Bledsoe B.P., Bowles C., Rubin Z., et al., 2012. Hydromodification Assessment and Management in California, Technical Report.

Sutherland R.A., Tolosa C., 2000. Multi-element analysis of road-deposited sediment in an urban drainage basin, Honolulu, Hawaii. Environmental Pollution 110: 483495.https://doi.org/10.1016/S0269-7491(99)00311-5

Taylor K., 2007. Urban environments. In: Perry C., Taylor K., editors. Environmental Sedimentology. Blackwell Publishing, pp. 190-222

Taylor K.G., Owens P.N., 2009. Sediments in urban river basins: a review of sediment-contaminant dynamics in an environmental system conditioned by human activities. Journal of Soils and Sediments 9: 281-303.https://doi.org/10.1007/s11368-009-0103-z

Trimble S.W., 1997. Contribution of stream channel erosion to sediment yield from an urbanizing watershed. Science 278: 1442-1444.https://doi.org/10.1126/science.278.5342.1442

Utz R.M., Hilderbrand R.H., 2011. Interregional variation in urbanization-induced geomorphic change and macroinvertebrate habitat colonization in headwater streams. Journal of the North American Benthological Society 30: 25-37.https://doi.org/10.1899/10-007.1

Vietz G.J., Sammonds M.J., Walsh C.J., Fletcher T.D., Rutherfurd I.D., Stewardson M.J., 2014. Ecologically relevant geomorphic attributes of streams are impaired by even low levels of watershed effective imperviousness. Geomorphology 206: 6778.https://doi.org/10.1016/i.geomorph.2013.09.019 
Vietz G.J., Walsh C.J., Fletcher T.D., 2016. Urban hydrogeomorphology and the urban stream syndrome: Treating the symptoms and causes of geomorphic change. Progress in Physical Geography 40: 480-492.https://doi.org/10.1177/0309133315605048

Wainwright J., Parsons A.J., Cooper J.R., Gao P., Gillies J.A., Mao L., et al., 2015. The concept of transport capacity in geomorphology. Reviews of Geophysics 53: 11551202.https://doi.org/10.1002/2014RG000474

Walling D., 1983. The sediment delivery problem. Journal of Hydrology 65: 209237.https://doi.org/10.1016/0022-1694(83)90217-2

Walsh C., 2004. Protection of in-stream biota from urban impacts: minimise catchment imperviousness or improve drainage design? Marine \& Freshwater Research 55: 317

Walsh C.J., Fletcher T.D., Bos D.G., Imberger S.J., 2015. Restoring a stream through retention of urban stormwater runoff: a catchment-scale experiment in a social-ecological system. Freshwater Science 34: 1161-1168.https://doi.org/10.1086/682422

Walsh C.J., Fletcher T.D., Burns M.J., 2012. Urban stormwater runoff: a new class of environmental flow problem. PLoS One 7: e45814.https://doi.org/10.1371/journal.pone.0045814

Walsh C.J., Fletcher T.D., Ladson A.R., 2005a. Stream restoration in urban catchments through redesigning stormwater systems: looking to the catchment to save the stream. Journal of the North American Benthological Society 24: 690-705.https://doi.org/10.1899/04-020.1

Walsh C.J., Fletcher T.D., Vietz G.J., 2016. Variability in stream ecosystem response to urbanization: Unraveling the influences of physiography and urban land and water management. Progress in Physical Geography 40: 714-731.https://doi.org/10.1177/0309133316671626

Walsh C.J., Kunapo J., 2009. The importance of upland flow paths in determining urban effects on stream ecosystems. Journal of the North American Benthological Society 28: 977990.https://doi.org/10.1899/08-161.1 
Walsh C.J., Roy A.H., Feminella J.W., Cottingham P.D., Groffman P.M., Morgan R.P., 2005b. The urban stream syndrome: current knowledge and the search for a cure. Journal of the North American Benthological Society 24: 706-723.https://doi.org/10.1899/04-028.1

Warrick J.A., Rubin D.M., 2007. Suspended-sediment rating curve response to urbanization and wildfire, Santa Ana River, California. Journal of Geophysical Research: Earth Surface 112

Wolman M.G., 1967. A cycle of sedimentation and erosion in urban river channels. Geografiska Annaler Series A Physical Geography 49: 385-395.https://doi.org/10.2307/520904 


\section{University Library}

\section{- M M I E E R VA A gateway to Melbourne's research publications}

Minerva Access is the Institutional Repository of The University of Melbourne

Author/s:

Russell, KL;Vietz, GJ;Fletcher, TD

Title:

Urban sediment supply to streams from hillslope sources

Date:

2019-02-25

Citation:

Russell, K. L., Vietz, G. J. \& Fletcher, T. D. (2019). Urban sediment supply to streams from hillslope sources. SCIENCE OF THE TOTAL ENVIRONMENT, 653, pp.684-697. https:// doi.org/10.1016/j.scitotenv.2018.10.374.

Persistent Link:

http://hdl.handle.net/11343/288180 